\title{
PUBLIC SPHERE DISRUPTION: PUBLIC SERVICE BROADCASTING AND THE CBC AT THE DIGITAL CROSSROADS
}

\author{
By \\ Scott William Baird \\ Bachelor of Arts, University of Ottawa, 2016 \\ A Major Research Paper \\ presented to Ryerson University and York University \\ in partial fulfilment of the requirements for the degree of \\ Master of Arts \\ in the joint program of \\ Communication and Culture \\ Toronto, Ontario, Canada, 2019 \\ (C) Scott William Baird, 2019
}




\section{AUTHOR'S DECLARATION FOR ELECTRONIC SUBMISSION OF AN MRP}

I hereby declare that I am the sole author of this MRP. This is a true copy of the MRP, including any required final revisions.

I authorize Ryerson University to lend this MRP to other institutions or individuals for the purpose of scholarly research.

I further authorize Ryerson University to reproduce this MRP by photocopying or by other means, in total or in part, at the request of other institutions or individuals for the purpose of scholarly research.

I understand that my MRP may be made electronically available to the public. 
Public Sphere Disruption: Public Service Broadcasting and the CBC At The Digital Crossroads

Scott William Baird

Master of Arts, 2019

Communication and Culture

Ryerson University and York University

\begin{abstract}
Public broadcasting is traditionally thought to be an essential element to public spheres. This paper charts how this relationship is formed, and then demonstrates how it is threatened in the Canadian context. Canada's public broadcaster, the Canadian Broadcasting Corporation, has digital policies like Strategy 2020: A Space for Us All which suggests CBC is pivoting away from its relationship with the public sphere, and in some ways weakening the Canadian public sphere. Accordingly, this paper looks at the claims charged about this policy, particularly from Taylor (2016), and considers how it and similar digital policies affect the CBC as an element of the Canadian public sphere. While the paper finds CBC digital policies benefit the public sphere, the majority put into action hinder CBC's relationship to the Canadian public sphere. Overall, this MRP highlights the importance of considering the philosophy of the public sphere when developing public media policy.
\end{abstract}




\section{Dedications}

Jim Baird (1956-2008)

To my father, academia has been an effort to ask questions you would like to be asking.

\section{Dr. Mahmoud Eid (1970-2017)}

To my academic and moral compass, thank you for the inspiration and guidance.

\section{Elda Baird}

Thank you, mom, for supporting me through everything. 


\section{Acknowledgements}

Thank you to the following people for helping shape my thinking during the whole of my time in academia:

Dr. Henri Habib

Prof. Joszef Orosz

Prof. Mike Stasko

Dr. Mahmoud Eid

Dr. Kyle Conway

Prof. Trevor Tucker

Dr. Matthew Tiessen

Dr. Jamin Pelkey

Dr. Catherine Middleton

Dr. Shannon Bell

Dr. David Skinner

Prof. Curtis Maloley

Prof. Michelle Schwartz

Dr. Art Bell

Dr. Jeremy Shtern

Niki Mohdar 


\section{Table of Contents}

Abstract.

1. Introduction 1

\section{The Public Sphere}

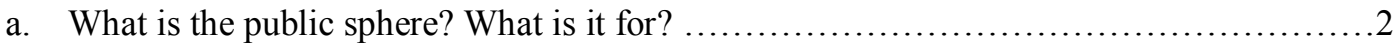

b. Criticism
i. A public sphere for whom? .4

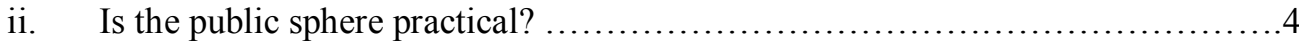

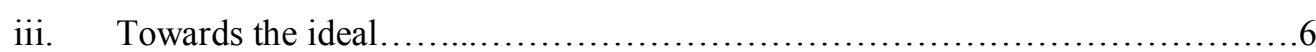

3. PSBs as an Important Element to the Public Sphere

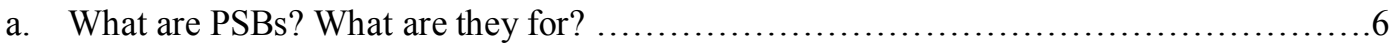

b. What PSB features contribute to the public sphere?

i. The Civic Model of Public Interest........................................

ii. Market Failures...................................................... 10

iii. Equalizing the Public Sphere........................................ 11

iv. Nationalism and Multiculturalism........................................ 12

4. CBC as a PSB

a. What Makes CBC a PSB ................................................. 13

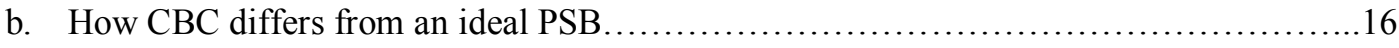

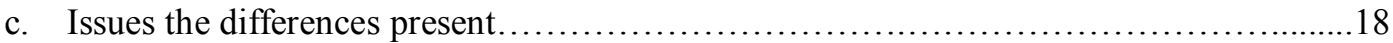

5. Public Service Media, or PSB 3.0

a. Shifting Dimension of Media............................................... 19

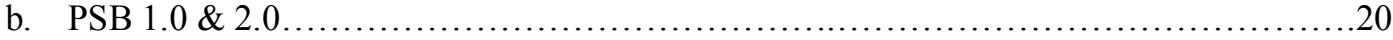

c. Public Sphere Goals for the ideal PSM

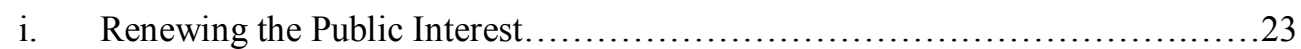

ii. Media Literacies....................................................24

iii. Diversified Accessibility.........................................25

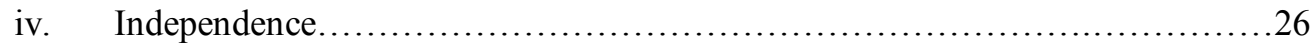

6. CBC and the Canadian Public Sphere in PSB 3.0

a. How Taylor's analysis demonstrates a conflict with PSB 3.0 in Canada...............27

b. How CBC Digital Policies Enhance the Canadian Public Sphere.......................32

c. How CBC Digital Policies Hinders the Canadian Public Sphere............................36

7. Conclusion: Improving PSB 3.0 in Canada

a. Operationalizing The Digital Commons for CBC in PSB $3.0 \ldots \ldots \ldots \ldots \ldots \ldots \ldots \ldots \ldots \ldots$

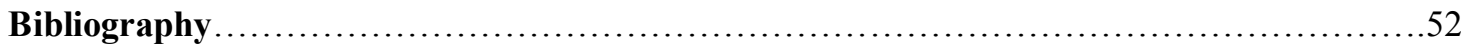




\section{Introduction}

It is typically argued that public service broadcasting (PSB) is an essential element to the public sphere (Garnham 1983; Scannell 1989; Tracey 1998; Savage 2010; Sorka et al. 2013; Burri 2015). However, digital technologies have served to disrupt the role of PSB in this regard, and in Canada, there is some concern that digitization may be undermining the Canadian Broadcasting Corporation's (CBC) — Canada's PSB — abilities to operate in this manner. For instance in a 2016 article, Taylor argues that the CBC's five year plan - Strategy 2020: A Space for Us All — will by 2020 disconnect the CBC from its role in the public sphere because the method program delivery "runs contradictory to the one-to-many nature of broadcasting," or in other words, $\mathrm{CBC}$ will focus on smaller and narrower publics, which Taylor says is "clearly contrary to the Habermasian concept of the public sphere, a forum where citizens engage as a singular 'public' with common issues of national significance" (p.357). Building on that concern this paper considers the question: do recent policy documents regarding the CBC enhance its role as an important element of the public sphere?

To answer this question, I will: offer

1. A broad and brief description of the concept of the public sphere as discussed in the literature.

2. Discuss how authors in the literature identify the contributions of PSBs to public sphere theory.

3. Analyze how CBC meets the criteria of the ideal PSB as described in the above literature; how $\mathrm{CBCs}$ differ from the ideal, and what differences suggest for the $\mathrm{CBC}$ going forward in the digital era.

4. Consider the shifting dimensions of PSB in the digital age and discuss the needs of the ideal PSB operating in digital.

5. Consider whether recent CBC policies like A Space for Us All and others will enhance or hinder its position as an element of the Canadian public sphere

6. Draw conclusions regarding directions the $\mathrm{CBC}$ might take to enhance its role as an important player in the Canadian public sphere. 


\section{The Public Sphere}

\section{What is the public sphere? What is it for?}

Public sphere theory refers to a conceptual "realm of social life where something approaching public opinion can be formed" (Habermas 2006, 73). Jürgen Habermas popularized the concept in his 1962 book The Structural Transformation of the Public Sphere, wherein he observes how eighteenth and nineteenth-century European men who frequented coffeehouses, salons, and taverns produced something novel by deliberating public affairs free from political constraint (Balnaves et al. 2014). Before the Enlightenment Era, public gatherings for discussing culture and politics in Europe were hardly anything of the sort since they were often mediated or controlled by institutional powers like the state and market. Separate from the state and market, the space for independently deliberating affairs and generating public opinion emerged.

We refer to the public sphere colloquially often as the "the arena of civic discourse" (Tracey 1998) which is thought to be the foundation of Western democracies. The foundation is where citizens produce discourse and debate, and where possible, they come to common ground on issues which instruct the nature of government laws and policies. So essential is this foundation to democracy, argues Benhabib (1992), that only legitimate governments are those that "listen to the public sphere" (p.87). In other words, the value of the public sphere is that it is the communicative process that culminates in citizens steering democracy in their interests instead of states or markets.

The public sphere is not a physical space in the way the theory's opposite, the private sphere - or what Habermas calls the "realm of commodity exchange" (Habermas 1989. 30) may be (i.e. shopping malls). As an abstract entity, the public sphere is a social process which functions as the "mediating instance between a society with its interests (sometimes divergent) and the state institutions that make political decisions" (Barro 2015). This abstraction is the 
buffering zone between the state and market where citizens (instead of consumers) share information, fact-check, and deliberate about issues pertinent to the state and market. The primary objective of this process is to produce public opinion, which is the currency of democratic activity.

Given that democracy refers to rule by the citizens, their opinions are thought to represent how the citizens wish to rule; however, Habermas is quick to remind, not all public opinion may be considered genuine or rational. In response to this problem, Habermas promotes the 'deliberation' mode of discussion. Deliberation ensures communicators are rational and ethical by forcing communicators to demonstrate a "willingness to let themselves be convinced by arguments" (Habermas in Conway 2009, 65). For that reason, Habermas awards deliberation as the "ideal speech situation" that allows for a "flourishing public sphere" (Mosco 2009, 151). By contrast, any indistinct conversation, debate, or argument, cannot be representative of the public sphere in action unless it has the ethical and rational qualities of deliberation, which in turn characterizes what people mean by democratic engagement. Therefore, we can think of the public sphere as a particular type of communicative infrastructure that upholds democracy.

In the same vein, we can similarly think of media systems as the infrastructure that generates and upholds the public sphere. The mass media, Michael Tracey (1998) says, "play a central role in providing social mechanisms for public dialogue on the common concerns of society' (p.13). Media systems, therefore, are like the vehicles that grant mass access to, and appropriate materials for, deliberating the everyday concerns of society. As a result, it is common to analyze media and broadcasting for how they enhance or hinder communication in the public sphere (Bailey 2007). In sum, the public sphere is an ethical and rational communicative process reliant on media systems for sharing information and deliberating arguments, which then develops public opinion that is used to shape public policy and the development of democratic society as a whole (Dahlgren 1997, p.iii). 


\section{Criticism}

\section{a) A public sphere for whom?}

However, academics still deliberate about the public sphere's existence. Some like Verstraeten (1994) view Habermas' description of the public sphere as emboldening the types of power Habermas imagines that the public sphere confronts. The public sphere Habermas spoke of was one that provided membership to -- and therefore political power -- exclusively to upper class, white, property-owning men. As a result, a Foucauldian description of the public sphere is visible whereby "a social disciplining and exclusionary function" takes precedence over universal and liberating caricatures ascribed to the public sphere (Verstraeten in Dahlgren 1997, 7). Moreover, those who own media systems that facilitate the public sphere tend to resemble the same structure of white, upper class, property-owning men. Various exclusionary and disciplinarian functions of the public sphere persist and characterize the theory's foremost critic, Nancy Fraser.

\section{b) Is public sphere theory practical?}

There is an array of groups that Fraser (1994) highlights as historically excluded from the public sphere like Indigenous, people of colour, LGBT+, and working-class peoples. These groups, Fraser says, often constitute their public spheres or 'counterpublics' that exist parallel to and perhaps in conflict with the normative public sphere that ends up instructing democratic decision making. Black Lives Matter can be a considered a counterpublic since their opinions, perhaps about the state's oppressive structures, exist in conflict with the opinions and demands of the public sphere that states listen to. In contrast, the Habermasian public sphere presents the public as an entity unified in character with similar demands for the state to act on, but in reality, Fraser says the public is "fragmented into a mass of competing interest groups" (Fraser in 
Grbeša 2004, 113). In other words, Fraser's critique of the public sphere is premised on the impractical notion of the public as a homogeneous entity.

As for Habermas' reflexivity, he sees the modern public sphere as compromised because of the co-opting of public opinion by consumerist oriented mass media. While the mass media may act as public sphere infrastructure, Habermas sees the mass media as responsible for the decline of public sphere's legitimacy, stating that "The world fashioned by the mass media is a public sphere in appearance only" (Habermas in Boeder, 2005). He concludes this because of how opinion flows in the mass media. For Habermas, communication is distorted from its ideal form in the mass media by transitioning communication from "debating culture to consuming culture" -- and in turn, it has contributed to the shaping of the public as consumers instead of citizens (Habermas in Örnebring 2007, 74). In the process, Petros Iosifidis says that Habermas identified how "The role of the media was central to the replacement of the ideal speech situation" by the distorting communication in service of the markets the public sphere is supposed to be independent of (p.2).

A useful example of this is the (contradictorily named) 'Citizens United' corporate lobbyist group. Citizens United helped equate corporations, or institutional power, as citizens in the United States by successfully lobbying for a ruling that defines corporate actions like financial contributions to political candidates as representing free speech. In other words, the ruling helps characterize an American public sphere where citizens and the market are not independent - thus perverting the concept of the public sphere in the US. Continued developments like these explain why Habermas speaks of the "refeudalization of power" whereby 'the public' also includes powers like markets which exert control over the public sphere that states respond to (Habermas in Conway 2009, 65). In other words, the public sphere 
has become less of an instrument to confront institutional power and more of an instrument for institutional power.

c) Towards the ideal

So, there are several angles to critique the veracity of the public sphere ranging from class, identarian, or consumerist perspectives. As a result, Grbeša (2004) says in Why if at all is the Public Sphere a useful concept that "The public sphere is an ideal model that has probably never existed" (p.116). However, Grbeša, like so many others who write about the public sphere i.e. Calhoun, Curran, Fraser, and even Habermas never discredit the theory completely. Grbeša's explanation of the continued value of the concept is the justification shared my most other critics too. She says that

If we think of the reasonable public debate as contributing to the ultimate goal of democracy - the biggest happiness for the greatest number of people - then we certainly must recognize the normative concept of the public sphere - together with its numerous adaptations and modification - as useful. The real challenge for democracy is how to measure up to this ideal as much as possible. (p.120).

In other words, much like how democracy is premised on ideals, the public sphere is also conceived in ideal terms that indicate the existence and strength of public spheres.

Hallvard Moe (2008) has mapped the primary ideals that comprise the public sphere. The first ideal element is equality, and wherein everyone has equal rights to express themselves and be listened to, free of constraints. Second, is reciprocity, which prescribes a duty to listen to others. Third, is openness, which permits the free flow of topics with no topics excluded and the relevancy of topics decided by the public sphere itself. Lastly, and where media infrastructure is most concerned, there is adequate capacity, which pertains to the ability to give questions and topics appropriate handling (Moe 2008, 324). Accordingly, when writers say PSBs are essential to the public sphere, typically they are referring to how they contribute to ethos Moe outlines above. 


\section{PSBs as an Important Element of the Public Sphere}

\section{What are PSBs? What are they for?}

There is another critical similarity found between the concept of citizens and PSBs. PSBs also share the same independence citizens have from market and state forces. Independence is baked into what makes PSBs distinct because they are, to varying degrees, independent from "from government, the state, and corporate commercial interests" which allow PSBs to foster "collective critical reflection on such powers" (Emden and Midgley 2012, 119). As a result, the public sphere and PSBs are similar in that they are both separate from the market and state. From this structural starting point, writers are able to justify their arguments that PSBs are essential to the public sphere because other forms of media are, to varying degrees, beholden to market (i.e. CNN) or state (i.e. Russia Today) ideologies, limitations, and structures, which are the areas of society the public sphere is required to deliberate upon.

Accordingly, there is an emphasis on PSB's relationship to the public sphere. Savage (2010) says that PSBs are "seen as a central mechanism for the information and cultural exchange key to a democracy, which, according Habermas, relies on a vibrant public sphere for discussion among the broader civil society" (Savage 2010, 273). Tracey (1998) agrees and says that "The classic western European model of public service broadcasting is seen as a deliberate expression for, and an understanding of, this role" (p. 13). In contrast, the commercial system, its role in contributing to the public sphere is underperformed because it "commodifies the audience role rather directly enhancing the democratic potential" (Savage. p.274). However, these are not static realities of media systems. According to Conway (2012), "there is no such thing as a pure public service or pure commercial system" since neither stop evolving in either direction (p.33). Nonetheless, several public media theorists, i.e. Raboy (1998), Rowland (2013), Sorka et al. (2013) all conclude that PSBs raise standards in ethics and practices from others in their media ecologies by encouraging private media to perform public services that 
benefit the public sphere. Raboy (1998) elaborates about the latent function of PSBs have on other media by saying "Private broadcasting can (and does in Canada) pursue public service goals ... however, it is unlikely that it would bother to try if not pushed in that direction by the competition and example of public broadcasters" (p.10). The contributions to the public sphere via public services are caused by PSB competition and also state regulation like in Canada, but it more accurately translates into a combination of both. In other words, PSBs "set the overall tone of the market, acts as a catalyst and serves as an example to all broadcasting services" (Ibid). These reasons help explain why Burri (2015) speaks of PSBs as the "the institutional guarantor and instrument of the modern public sphere" (p.8) since they can enhance the contributions of other media to the public sphere in addition to their unique contributions.

\section{PSB contributions to the Public Sphere}

\section{The Public Interest}

PSBs employ an array of unique practices that contribute to the public sphere. According to Burri (2015), Nicholas Garnham was the first academic to identify that PSBs are essential to the public sphere because the way PSBs serve the public interest "is better for human liberty and democracy" (p.10). For Garnham, the public interest that PSBs serve represents the “imperfect realization of Habermas's ideal," because they help engineer a "space for a rational and universalistic politics distinct from both economy and the state" (Garnham in Grebša 2003, 116). Other authors have also explained what the characteristics of the PSB public interest means. Mosco (2009) maps the breadth of public interest as a term:

\footnotetext{
With roots in the law governing regulation of the communication industries. The notion has received extensive treatment, including criticism for ambiguity, particularly when set against the seemingly clearer test of the marketplace. The public interest idea nevertheless survives in law, though the process of commodification has weakened its standing. It also survives in research as an extension of the public sphere notion to refer to those interests that transcend commercial gain and consumerism (p.152)
}

It is those interests that circumvent consumerism that Garnham is referring to that best serve liberty and democracy. 
This is the public interest that Rowland (2013) defines as the Civic Model of Public Interest. As civic institutions, PSBs view the public as citizens instead of consumers, as residing in the demos and not the market, and thus requiring a media that serves citizens in the public sphere instead of advertisers in the private sphere (p.8). Since their programming are not tied to the needs and interests of advertisers, PSBs perform public services that cultivate "informational, cultural and social benefits to the wider society which go beyond the immediate, particular and individual interests" (McQuail in Jakubowicz 2010,9). These are benefits beyond the scope of profitability for most private media, but plenty of evidence suggests that the public service way of creating and delivering media produces the qualities more conducive to a vibrant and functional public sphere.

Gardener (2017) offers a history of public broadcasting through a review of the literature about the social effects of PSB programming that illustrates this point. She found that PSB programming tends to: cover more international, domestic, and public policy issues than private counterparts; PSB programming is less sensationalist, consumers of PSB programming are likelier to vote; PSB audiences tend to have opinions of crime and immigration that align with scientific data instead of hyperbole and propaganda, and they tend to hold less extremist political views; and perhaps most reflective of the how PSBs create equality in the public sphere, is that PSBs tend "to minimize the knowledge gap between advantaged and disadvantaged people, leading to more egalitarian societies" (Gardner, 2018).

These qualities are unsustainably provided by what Rowland (2013) calls the Market Model of public interest. Rowland defines the breadth of what markets are interested in as concerning arbitrarily and ill-defined 'large' audiences, topics and people compatible with the sponsor's message, and adherence to the ideology of consumerism in programming content (p.22). Additionally, sponsors often collaborate in programming productions to ensure those interests are met (Ibid). So, if a private broadcaster is to perform public services, it will demand 
of them to provide something "that goes well beyond satisfying consumer demand" (Spigelman 2013, 48), which is less profitable than what private media could otherwise offer to advertisers. In other words, it is more costly for private broadcasters to focus on the public services that directly benefit the public sphere.

The outcome is that peoples and topics outside the realm of profitability are more likely to be underserved - and they are therefore likely absent from public sphere discussion. States usually impose regulations on private media for such reasons; however, in Canada for example, while private broadcasters are regulated to ensure they apply the PSB view of the public interest, according to Canadian media scholar Phillip Savage, regulation has historically "sided with safeguarding large media conglomerates' commercial interests while public broadcasting interests fall behind" (Savage 2010, 275). At the heart of this problem is the enforcement of unprofitable behaviour on a system that sustains itself through a pursuit of profit. In sum, the

Civic Model of public interest defines how PSBs view and serve the public in their programming, which in turn contributes to the public sphere in more significant and sustainable ways than what the Market Model of public interest can reliably provide for broadcasters. These are called 'market failures.'

\section{Market failures}

Burri (2015, p.24-25) maps the breadth of market failures which include at least six features that elicit the need for PSBs. First, is that PSB's initial role was to ensure public purposes of scarce airwaves; this may be interpreted today as ensuring that there are sufficient public service purposes of cable and internet technologies. Second, is to provide adequate programming that serves citizens as opposed to advertisers. Thirdly, PSBs mitigate monopolistic or oligopolistic media systems because unregulated markets tend to reduce competition and leave fewer choices for the public and at higher prices. Fourthly, since markets are risk-averse they tend to provide the tried and tested types of informational and entertaining 
programming; as a result, PSBs emphasize diverse, risky, and untested programming, which Rowland (2013) says allows for citizens "to be surprised, and for taste and interests to be developed" (p.21). In turn, this tends to culminate in profitably-risky programming like ones that "disturbs, challenges, provokes thought, inspires, or is locally relevant" (p.29). Penultimately, private media tends to prefer audiences that elicit passive indulgence of programming, so in contrast, PSBs prefer audiences that are politically active or that have the potential to be politically active (Conway 2012). For that reason, PSBs programming tends to focus on democratic and educational programming. Lastly, PSBs are interested in cultivating merit goods. These are things like educative programming, platforming the arts, or research tools like archives that develop "long-term benefits but which no individual thinks worth paying for" (Conway 2009, 72). Burri's examination of market failures helps illustrate how wideranging the failures are and what the limits private media have in providing goods in the civic model of public interest.

\section{Equalizing the Public Sphere}

Despite PSBs filling gaps in the public sphere generated by the market, Habermas has never favoured any type of broadcasting over another but instead desires a media system that has the means for achieving "pluralism and a vibrant, meaningful public discourse in society" (Burri, p.10). Conversely, Paddy Scannell (1989) argues that PSBs have done precisely that. Scannell argues that the public sphere cannot be said to be an equal and accessible space for the majority of the people until the arrival of PSBs because they "unobtrusively contributed to the democratization of everyday life" through its commitment to universal availability (Scannell in Grbeša 2004, 116). Moreover, couched in PSB universalism was a gradual representation of all social groups (Ibid), which therefore shows PSB's ability to serve and platform marginalized communities that populate counterpublics. Scannell says that before PSBs, media systems of the public sphere had "not always given consideration to all subjects and peoples" (Ibid), which 
points to how PSBs cater to those normally voiceless (perhaps as a consequence of market failure) in the public sphere. Albeit, this has not always been the case, which Conway (2012) and Bailey (2007) both highlight because PSBs has been used extensively to enforce class hierarchies in the early years of PSB. Nevertheless, a pattern of redeveloping its structure to include more voices and people represents an ethos of public broadcasting that is much like public sphere theory in that it is continuously in refinement towards a more ideal state. Overall, PSBs can be thought of as an important tool that has pushed the public sphere towards existing closer to its ideal form as illustrated by Moe (2008).

Specifically, there are three things Scannell identifies that demonstrate how PSBs have pushed the public sphere closer to its ideal state. First, they brought "public life into private life" by broadcasting public events into the homes of the general public; second, they brought "private life into public life" by increasing the diversity of voices and perspectives made available for public consumption; lastly, PSBs have pushed the boundaries of topics considered acceptable for public discussion (Scannell in Conway 2009, 66). The result is that "public life was equalized in a way that had never before been possible" (Scannell in Grbeša 2004, 116).

The equalizing force that PSBs bring to the public sphere is also reflected in the mandates of all PSBs. To a large part, mandates often draw from the mandate of the BBC generally seen as the first PSB. Included in that mandate, founding director John Reith instructed the $\mathrm{BBC}$ to inform, enlighten, and entertain the public by bringing "into the greatest number of homes everything that was the best in every department of human knowledge, endeavour, and achievement; and to avoid whatever was or might be hurtful" (Burri 2015, 191). This resulted in PSB creating programming that includes natural history, education, news, current affairs, science, children's programming, the Olympics, along with every genre of music and entertainment which were all delivered free-at-point-of-use via Over The Air radio systems for the whole of the nation (Gardner 2018). By providing all these programs universally and 
couched in humanist themes, PSBs satisfy what Rowland (2013) calls the need "for social cohesion and act as a civilizing influence" (p.51). In other words, PSBs have been an instrumental tool for equality and social cohesion required within the public sphere.

\section{Nationalism and Multiculturalism}

Rowland (2013) identifies the two important concepts the PSBs rely on which also happen to characterize how PSBs fulfill equalizing and social cohesion outcomes. The first is Benedict Anderson's "imagined communities" which is derived from how we "create and maintain communities both large and small out of a desire to provide necessary conditions for civilized life," or nationalism (p. 10). Second is Emile Durkheim's organic solidarity, which posits that modern societies derive social cohesion and interdependence from our specializations and diversity (Ibid), or multiculturalism. Taken together, nationalism and multiculturalism reflect what Murdock (2004) identifies as emblematic of most PSB programming, which is that it tends to ask, "What is it like to be someone else, to be particular kinds of other people?" (Murdock 2004, 6). These types of programming explain why sociologist Richard Hoggart says that PSBs allow for the "nation to speak to itself" (Tracey 1998, 29). In other words, through a national and multicultural framework, PSBs provide the opportunity for all the citizens of the country, in all its diverse demographics, to deliberate.

\section{CBC as a PSB}

\section{What makes CBC a PSB?}

The CBC generally fits the description of a PSB. Included within The Broadcasting Act (1991) is the 'Reithian Trifecta,' which instructs CBC to 'inform, enlighten, and entertain' Canadians by being distinctly Canadian, universally available, multilingual, multicultural, regionally accessible, and it must contribute to a sense of national consciousness (Sect. III). Here we can see $\mathrm{CBC}$ as an instrument for socially equitable and beneficial services for all 
Canadians by emphasizing macro and minority contexts of national, multicultural, linguistic, and regional demographics that provide the basis for a pluralistic public sphere in Canada.

CBC programming often demonstrates that it is the type of media that authors above have described as essential to democracies. As the most widely accessible and trusted form of media in Canada CBC has enjoyed a history which Taylor (2016) says is "central to Canadian cultural life" (p.353). Often, CBC programming is a catalyst for launching discussions about under-discussed issues like the Missing and Murdered Indigenous Women and Girls epidemic. In $2016 \mathrm{CBC}$ began cataloguing the epidemic and creating an interactive database of more than 300 women affected in this epidemic (CBC News 2019). This has been an effective way to help elevate awareness about the MMIWG movement, and it progresses goals within the reconciliation movement in Canada with Indigenous peoples and the history of colonialism by platforming MMIWG to national significance. Moreover, $\mathrm{CBC}$ is also instrumental in cultural exchange, like when in $2016 \mathrm{CBC}$ aired the final performance of Canadian cultural icon Gord Downie for three commercially-uninterrupted hours where 11.7 million Canadians, or about a third of Canada, engaged simultaneously in the programming of national and cultural unity (CBC News Aug. 2016). Fittingly, included within that performance was a speech about reconciliation and the MMIW epidemic.

$\mathrm{CBC}$ also maintains an interesting structural purpose in Canada. PSBs often respond to market failures, but there is one overbearing market failure in Canadian broadcasting: it is more profitable for Canadian private broadcasters to recast American programming instead of producing and promoting productions about Canadian culture and politics. Many argue the embrace of American cultural programming is the market failure that elicited $\mathrm{CBC}$ into existence in the first place, given that upon the CBC's arrival in the 1930s American programming was threatening to engulf Canadian airwaves (Conway 2012). The influence of American cultural programming remains strong to this day in Canadian media, but it would 
likely be more dominant without CBC's Canadian productions and by proxy the Canadian productions that its private competition produces in response. However, in prime-time hours, i.e., when Canadians generally get home from work and most watch television, $\mathrm{CBC}$ has nearly 90\% of Canadian productions occupying programming schedule, whereas CTV, one of its main private counterparts, has quite little and on some days has zero Canadian productions airing and instead airs American programming (A Creative Canada, p.8). Oddly then, in some regards, providing Canadian cultural programming to Canadians can be considered a public service which is a rather unique problem. In light of this reality, CBC's performs an essential function for the Canadian public sphere by ensuring it has significant and varied programming that reflects its nation.

There are also several other types of market failures impacting Canadian media that $\mathrm{CBC}$ responds to, which all contribute to multiculturalism in Canada. First, as a bilingual country, $\mathrm{CBC}$ is formally known as "CBC/Radio-Canada," and as such it provides programming to minority French Canadians in their native language. There are other provisions too for Indigenous minorities, and some of this programming is delivered in various Indigenous languages (Taylor 2016). Next, there are regional gaps like communities outside more profitable metropolitan areas. Notable in this category is Thunder Bay, which despite a population over 100,000 it has had a turbulent time maintaining its local media coverage in the digital era with some private stations even surviving on life insurance policies instead of revenue (Kohut 2016). Because of the unprofitability of local media like those in Thunder Bay, $50 \%$ of all Canadian local television are at risk of going off the air by 2020 (Pedwell 2016). CBC is therefore required to increase its presence and resources in areas like Thunder Bay where the private market is vacating. Lastly, in the most northern areas of Canada, there are geographic gaps for which there are no private media at all covering its news and culture. In response, CBC dedicates a "CBC North" division to provide relevant programming for these areas like in the 
Yukon and other territories. Due to this diverse commitment to various minority communities, Conway (2012) agrees that CBC is a good representation of PSB's commitment to diversity which he says is "especially strong in countries like Canada where multicultural groups are significant, and their communities are reflected in CBC programming (p. 43). In sum, CBC is the central mechanism that allows minority communities in Canada to exchange the information and culture that are necessary for an equal and universally accessible Canadian public sphere.

\section{How CBC differs from the ideal PSB}

Despite its significant similarities to traditional PSBs, Taylor (2016) accurately says that Canada has never been "all in for public broadcasting" (p.353). That is because CBC is not a fully funded PSB, meaning unlike the $\mathrm{BBC}$ and most other PSBs the $\mathrm{CBC}$ is funded on an annual basis and derives a portion of its revenue from television advertising. This vulnerability is not present for $\mathrm{BBC}$ which receives fixed appropriations on 10-year cycles that can circumvent political and economic pressures whereas CBC's funding is more influenced by political and economic winds than an ideal PSB.

The period following recession of 2008 demonstrates how problematic the lack of significant and fixed-term parliamentary appropriations can be. With the recession eliciting increased government fiscal tightening, funding for the CBC saw a precipitous decline. In 2008 CBC received 1.2B, but by 2014 it fell to $\$ 715 \mathrm{M}$ (Ibid). By 2010 commercial revenue soared to a third of all CBC revenue (Armstrong 2010, 25), and by 2014 only 55\% of revenue came from parliamentary appropriations (Taylor, 353). Cases like these demonstrate CBC's hyper vulnerability to economic and political pressure and how it departs from the PSB ideal of independence from state and economy.

In Wade Rowland books that cover CBC (2013; 2015) argues that CBC needs independence similar to the BBC's which has more of a separation from state and economy through fixed government appropriations that allow for ad-free programming. Without such a 
structure, Rowland's analysis identifies how CBC is more vulnerable to forego responsibilities to the civic model of public interest. This is what happened under the tenure of the former $\mathrm{CBC}$ president of English services Richard Stursberg. Coming from private media roles Rowland (2013) says that Stursberg led the CBC with goals similar to the ones he had in previous positions, namely those arriving from the market model of public interest. As a result, the new goals of the $\mathrm{CBC}$ were to garner the most attention from viewers and the most interest from advertisers, and to ensure the financial success of this new model, Rowland writes that under Stursberg "talk of public service mandates were banned" (p. 28).

However justified Rowland's critiques may be, these other market-oriented changes are sometimes necessary for the $\mathrm{CBC}$. When recessions happen or when hostile governments form and attack $\mathrm{CBC}$ 's budget, it becomes more necessary for $\mathrm{CBC}$ to adopt market-minded strategies to ensure both financial and existential sustainability. Moreover, how meaningful increased market revenue is to CBC's ability to serve the public sphere is debatable because the private revenue sources are still put in service of public purposes, rather than for profitable purposes. Nonetheless, it does suggest a weakness within the structure of the CBC that leaves the organization vulnerable to veering away from the PSB community. Limitations in serving the public interest is not a problem omitted from CBC management either. Former CEO Hubert Lacroix has mentioned there needs to be a more significant budget to ensure $\mathrm{CBC}$ can continue to "focus" on its public service mandate (Lacroix 2017). So have previous CEOs, including Tony Manera in the 1990s who first sounded this alarm of the consequences falling parliamentary appropriations will have on the CBC. Manera elaborated about the contradiction of CBC's budget cuts by saying "Cuts of this magnitude should not be made without Parliament changing the CBC's mandate ... It's just ludicrous to suggest that you can keep the same expectations and keep cutting the funds - it's a vicious circle" (Chidley and Turbide, 1996). This vicious cycle will likely continue to create confusion and problems in CBC activity in 
terms of what type of programs it produces, the types of audiences it seeks, and with what methods it deliveries its programs. In sum, without a stable funding structure, $\mathrm{CBC}$ is prone to periods like Stursberg's where there is increased pressure to adopt market dynamics and increased difficulty emphasizing the civic model of public interest that make up an ideal PSB.

\section{Issues the differences present}

At the core of CBC's problems as an ideal PSB is the unfavourable attachment to private sources of income along with unstable public funding structure. Yet, the financial structure has not meant that $\mathrm{CBC}$ is not a PSB because it is still able to accomplish its public service goals to an astonishing degree. Taylor's description of this makes it clear that

in many ways it is amazing the CBC is able to provide the services it does to Canadians. CBC/Radio Canada offers television, radio and online services, in both official languages, as well as First Nation's languages in the far north. Despite showing the bruises of the last decades, the CBC by and large remains, as observed by UK scholar Richard Collins in 1990, 'the flagship of Canada's communication and cultural policy' (p.354).

Although, what the precarious financial structure should suggest is that this remarkable run Taylor describes is not indefinitely sustainable, and thus suggests pivot changes on the horizon for the could push CB closer to the ideal PSB, or potentially remove it from PSB community entirely.

The instability is drawn from digital environment developments which suggest CBC is likely at structural cross-roads in its funding, and consequently as a significant element of the Canadian public sphere. Firstly, its parliamentary appropriations are at risk once again: the positive net benefits $\mathrm{CBC}$ has received lately from increased parliamentary appropriations since 2015 (in response to the cuts it experiences following the recession) will by 2022 be completely lost due to inflation (A Creative Canada, p.16). Additionally, it is unclear how much more willing the current government is to increase funding. Secondly, it is clear that the opposition formed government, according to its party leader, is interested in significantly minimizing appropriations $\mathrm{CBC}$ out of a belief that it should not be producing news (Dickson, 2016). Thirdly, while public funds are stagnating and potentially decreasing with a change in 
government, commercial digital revenue is not appearing to viable, long-term solution to recoup revenue gaps; that is because an estimated $82.4 \%$ of all digital ad-revenue made in Canada migrates to the coffers of Facebook and Google instead of the media companies reliant on those ads for funding (The Shattered Mirror, p.30). Moreover, this makes matters more troubling for the rest of Canadian media which are increasingly more digital and therefore increasingly more reliant of the small pool digital ad revenue that $\mathrm{CBC}$ also competes for. Overall, both private and public revenue streams are under threat, and so it appears more likely that without substantial changes to its funding structure, $\mathrm{CBC}$ 's independence from the economy will become smaller, which in turn would have adverse effects across Canadian media. Put another way, without substantial changes to Canadian media, the infrastructure that upholds the Canadian public sphere will be severely damaged.

\section{PSBs in Digital, or PSB 3.0}

\section{Shifting Dimensions of Media}

$\mathrm{CBC}$ is not alone among other PSBs requiring significant changes in the digital era. Many are recalibrating amidst similar disruptions. It is a part of the wider shifting dimensions of the media environment are drawn from what Jakubowicz (2010) calls the development of third era of broadcasting, or 'PSB 3.0' which is characterized by 'PSB + all relevant platforms + Web 2.0" (p. 14). This means in addition to conventional forms of broadcasting (Over The Air, television, radio), PSBs also operate in the multi-platformed, collaborative, user-generated, mobile, and delinearized Internet environment, which has resulted in various policies reshaping PSBs under a new label of 'Public Service Media' (PSM). As a result, there is pressure for PSMs to identify where they belong, or what its distinguishing features are, in comparison to private digital media which are highly saturated and innovative in the digital environment. Therefore, there is at least an implicit notion today about the media environment that "PSB is 
anachronistic" due to the supposed emancipatory qualities the Internet has on the marketplace (Gardner 2017, p.9), or that PSB "is an institution of the past” (Burri, p.1).

And yet, the distinction PSB continues to provide in the media environment remains obvious. The digital era has seen the types of dysfunctional developments within the public sphere that PSBs are interested in confronting, including postpoliticalism, social decohesion, failing media business models, and oligopolistic media (Jakubowicz 2010; Burri 2015; Gardner 2017). It is quite clear that the public sphere in the digital era is in crisis, and so the continued relevance of organizations like $\mathrm{CBC}$ can use the crisis to demonstrates how its values and practice might act as a corrective for dysfunctional public spheres. As a result, if handled carefully and ambitiously, PSB 3.0 could be an era for PSBs to demonstrate the essential ties it has to the public sphere - and there is precedent of PSBs doing something similar to this. To explain this precedent and how it could help PSM policies that target the needs of the public sphere, it is first necessary to cover how the institution developed in the previous two eras.

\section{PSB 1.0 and 2.0}

Jakubowicz (2010) says that PSB 1.0, most characterized by the use of Over The Air technologies, was a period of about 60 years where PSB faced little commercial competition (p.9). Most importantly though, beginning in the 1920s there began an explicit social purposing of broadcasting with significant precedents pioneered by the BBC (p.1). In 1922 the BBC began, Bailey (2007) says, as a reaction to "a growing problem within the declining public sphere: the problem of an uninformed electorate" (p.100). Bailey's description of Reith and his motivations paints the founding director of the $\mathrm{BBC}$ as concerned with the tendency of post-politics within democracies, and that PSBs could be a force mitigating the impulses that lead to inactive public spheres.

The term 'post-politics' has its origins from thinkers like Žižek (1999), Rancière (2004), and Badiou (2008) who have elevated the term to describe a dysfunctional feature of 
democracy whereby citizens struggle to produce basic functions like political engagement or electoral participation. Jakubowicz cites the term as a central concern for PSB 3.0 strategies, and she defines post-politics as a "disinterest in civic duty, political engagement or activism" (p.10). This tendency is describing the vulnerability of public spheres and therefore the viability of democracies. Uncoincidentally, the BBC at this time not only helped pioneer the notion of creating media for explicitly for citizens, but also for those "who at least have the potential to become active" (Conway 2012, 43). PSBs, in other words, are a tool to buffer against postpolitics.

This begs one to ask why there was a noticeable post-political crisis in the period prior to the BBC and other PSBs? One intelligent answer comes from BBC historian Jean Seaton. Speaking on the social currents that foregrounded the creation of public broadcasting, Seaton says that

There was a real sense of a kind of moral corruption around the media. There was hostility towards politicians, and a sense that politics was compromised and damaging. And also a kind of post First World War anxiety about commerce and big business. And out of those three things that we don't want, comes one thing we do: the impulse that you must attempt to deal with the public in a more straightforward and honest and informing way (Seaton in Gardner 2017, 12).

In other words, the general mood among citizens in public spheres (particularly of Europe) reflected a deep distrust of states and economies but also the media responsible for facilitating vibrant and active public spheres. This represents a fundamental breakdown of social order. Solving this problem required more than simply doing away with sensationalism in media that Seaton concludes. PSBs also had to facilitate a social climate for politically active citizens, which Bailey (2007) says translated into a "core rationale of all broadcasting" which is "that it is useful to unite the public around cultural values and practices that breed a sense of national citizenship, identity, and a sense of belonging” (Bailey 2007 p.100). In other words, one of the primary purposes of PSB 1.0 was the fostering of social cohesion and political activity necessary for functional public spheres. 
However, around the 1980s PSB 1.0 gave way to PSB 2.0. Writing in 2010, Jakubowicz calls this the "remaining period of flux" whereby cable, satellite, and internet services have given way to a proliferation of commercial competition (p.9). At this historical moment, governments gave themselves fiscal (but not social) licence to begin a project of relinquishing public programs for commercial market interests, and PSBs were not spared. The result for most PSBs has been a virtual freefall in budgets for many PSBs. For instance, from 1985 until the early 2010s, Canada's PSB experienced a precipitous fall in funding culminating in over a $\$ 1$ billion in financing cuts from what parliamentary appropriations had once been in PSB 1.0 (Friends of Canadian Broadcasting, 2014). Identical stories of falling budgets and the anxiety surrounding PSB organizations are told in Michael Tracey's 1998 polemic eulogy The Decline and Fall of Public Service Broadcasting which details the changes and effects PSB 2.0 had on PSBs around the world.

One of the primary effects of surgent private broadcasters has been the growth of the governance of broadcasting under the market model of public interest. Jakubowicz speaks of this by saying that PSBs and the culture of broadcasting had been "dethroned by the very commercial and individual interests it seeks to traverse" (p.9). In turn, the market model became more dominant, and there grew alongside it the effects that the civic model attempts to confront, namely the postpoliticalism highlighted by Bailey (2007) and social decohesion highlighted by Seaton. One significant study demonstrates a rise of these dysfunctions in democratic society during the same period of PSB 2.0 from the 1980s to the 2010s. According to World Values Surveys, carried out by political scientists Yascha Mounk and Roberto Foa, in the past 30 years citizens of nearly every country in democracies have been "less likely to agree it's essential to live in a democracy," each new generation has been less supportive of democratic ideals and institutions than the last, and the survey finds a rising percentage of "people who approve of having a strong leader who doesn't have to bother with elections" (Gardener 2017, 11). 
Additionally, Jakubowicz specifically attributes the new logics PSB 2.0 media and broadcasting as contributing to a resurgence of another "post-political crisis among citizens" (p.10). What this study and the effects of PSB 2.0 make clear is that democracy must be maintained through public policies, not taken for granted by growing markets, which includes ensuring the infrastructure that upholds the public sphere and therefore democracy, such as PSBs, remains robust.

This the cultural context that PSB 3.0 must meaningfully contend with in fashioning an era distinct from PSB 2.0. Given that the current post political and socially discohesive environment is familiar to the era that elicited PSBs, we can understand what Jakubowicz means when they write that PSB 3.0 should be "The version of PSB that we would create today if it had never been created" (Ibid, p.9). Another way of putting it is that PSM need to adopt what Golding (1990) calls a "philosophy of communications which locates and understands the role of communication processes and institutions in the public sphere" (Golding in Gauthier 1997, p10).

At the time of publishing their article in 2010, Jakubowicz spoke of PSB 3.0 as still developing its norms different from PSB 2.0. However, the norms that we so far see it does not appear to reflect an organized effort to fashion media system that consider the public, but rather it reflects a continued yet uniquely alarming erosion of the public sphere. Techno-sociologist Zeynep Tufekci describes a scene where media is corroding the public sphere because media environment is marked by

the multitude of people and institutions with the capacity to broadcast, each with different normative standards - and some with no concerns about accuracy even as a standard that is not always upheld - with a polarized public with little trust in any intermediary and drawn to information that confirms preexisting biases. The result is a frayed, incoherent and polarized public sphere (Tufekci in Gardener 2018).

Therefore, if PSM are going to create a meaningfully distinct PSB 3.0 era, then it should consider the ways in which broadcasters like the $\mathrm{BBC}$ responded to similar crises with the public sphere during PSB 1.0. Burri (2015) also agrees and writes that the goals of PSMs must be 
centred on the "underlying public interests objectives, which is nothing less than sustaining the public sphere" (p. 161). Clearly, what is asked of the PSB 3.0 era is to put into practice Golding's idea of a media with a cogent public sphere philosophy.

\section{Ideal PSM Contributions to the Public Sphere?}

What then could be determined as necessary to a public sphere philosophy for PSM? One observation from the advocacy group Public Service Media Alliance believe that the mission of PSM is to renew historical PSB values, like those diminished during PSB 2.0, while tackling new challenges and opportunities particular to the digital environment. For this organization PSM "retains the core ethos of public service broadcasting while enabling public service broadcasters to engage with audiences via new media platforms." There are four areas of interest can be gleaned from the literature help illustrate what historical values and new policies PSM ought to focus on in the development of their digital era policies. They include: the civic model of public interest, media literacy, diversified accessibility, and independence. Each of these are essential attributes to a public sphere philosophy for PSM concerned with the public sphere in the digital age.

\section{Renewing Civic Model}

One of the central frameworks for a reinvigoration and amplification of the civic model in society is Graham Murdock's concept of the digital commons. The concept calls for a 'public sector convergence' whereby PSBs act as the "central node" or the digital commons, for all institutions that operate in the civic model of public interest. The idea is to create "a new network of public and civil institutions that together make up the digital commons, and a linked space defined by its shared refusal of commercial enclosure and its commitment to free and universal access, reciprocity, and collaborative activity" with the public broadcaster "making up the 'central node' in the network" (Murdock 2004 in Jakubowicz, 12). The intended outcome for the concept is to form "the basis for new shared cultural space, a digital commons, that can 
help forge new communal connections" (Murdock 2004, 4). With this approach, PSM policy could operationalize a way to reinvigorate both political participation and social cohesion by organizing civic-minded institutions collectively by strengthening with resources and give more prominence to organizations operating in the civic model of public interest. Due to the reach, trust, and accessibility of PSBs, this would be the ideal way to enhance all civic-minded organizations.

\section{Media Literacies}

Similar to how Scannell identified that PSBs helped equalize the public sphere, PSM ought to consider how it can be a force for equalizing the participation of the citizen in the public sphere. Digital technologies, for which Tufekci's earlier description of the public's 'different normative standards' of media makes clear, stratifies the civic and political potential amongst those more literate with new media technologies and those less so. For that reason, PSM policies ought to target "education gaps present in how people engage with media" (Jakubowicz, 15). The PSM curriculum that Jakubowicz identifies is one which targets literacies in technology, information, media creation, and globalization (p.13-15).

Educative programming should also be operationalized to target audiences who are already negatively stratified by the status quo of digital media. Gardner (2017) speaks of this phenomenon whereby the educated, affluent and the already-most-engaged citizens are amplified and most targeted on various digital platforms through 'narrowcasting' content to those audiences. Digital private media deliver specific content to the affluent and educated audiences, she says, because they are the ones who can most "pay for subscriptions" or whatever products under consideration (p.13). In other words, there will be a gap in the public sphere generated by platforms like Facebook that cater mostly to certain sets of audiences. Without a strategy that "programs against" narrowcasting, Gardner says, and she adds that That's not great for democracy: We can expect to see a growing gap in political knowledge and participation" 
(Ibid). It is incumbent on PSMs, therefore, to do what Gardner says is to "program against" the audiences ignored by narrowcasting and promote programming which would benefit from programs drawn from the curriculum outlined by Jakubowicz.

\section{Diversified Accessibility}

Third, while the proliferation of digital mobile services may be popular, it is not the ubiquitous mode of media use. Digital adoption has not become a universal nor exclusive medium. While younger generations may be more likely than older ones to use mobiles and access digital platforms like Google and Facebook, a majority of 18-24-year-old access news from tv, radio, and the web collectively and only a minuscule 5\% exclusively use social media for news (Newman, N. and Fletcher 2017, p.149). This is a familiar phenomenon, too. Historically, new communication technologies are often attached with rhetoric that suggests the old ways of communicating are over. Yet as a historian of communication technologies, Rowland (2015) writes, the introduction of a new communication technology does not replace the former, "Radio did not replace the telephone, television did not replace radio, and so on" (p. 169). Such a problem is this tendency to quickly discount certain technologies over others - and therefore its audiences - that the Public Service Media Alliance includes in its mission statement that PSM policies must enable "access and interact with free, independent, engaging and relevant content whether they are in rural or urban environments, irrespective of economic status or access to technology" (Public Service Media Alliance 2018). Therefore, PSM policies must handle their presence and resources in traditional platforms in the digital era carefully, because they risk the potential of inducing more social dysfunctions like exacerbating socioeconomic inequalities as a result of differential access to, and literacy with, digital technologies. In other words, PSMs must not view the technological future with simplistic, onedimensional visions but rather maintain diverse technology to ensure mass access to the public sphere. 


\section{Independence}

Lastly, independence is at the heart of what makes PSB unique, so some thought should be given how PSB independence is undermined in the digital era and the ways in which it could be strengthened. Using digital applications is a largely monopolistic experience run by market media intermediary platforms like Google and Facebook. Both have significant influence in how information flows in the online space and generally dictate how algorithms curate the delivery of content and programming to users. Those algorithms are also built to service the interests of Facebook or Google, and according to a study by Newman and Fletcher (2017), the content or programming that is rewarded with attention from users tends to be those that tightly conform to a logic of short, emotional, and visually stimulating content (p.149). There is concern, therefore, that occupying spaces like Facebook can result in mimicking sensationalism practices that betray some founding principles of PSB. Overall, there is no profitable reason for digital platforms like Facebook favour PSB principles, such as the civic model of public interest, as they are not regulated to do so. The ideal PSM strategy that assures independence, therefore, will preserve presence on regulated channels like cable and radio, and consider ways to deliver digital content outside third-party private whose goals are divorced from the civic model of public interest.

\section{CBC and the Canadian Public Sphere in the Digital Age}

A Space for Us All is a plan that shifts CBC operations to the point where it “increasingly serves Canadians via digital streaming services designed for mobile devices" (Taylor, p.350). The pivot to a more digital dominant approach to delivering its mandate is drawn from the financial and logistical challenges that digital platforms are inducing within the Canadian media environment. "Apple, Google, Facebook, Amazon, and Netflix," are the organizations the document cites as responsible for the situation where "space reserved for Canadian voices is more fragmented," which in turn is putting "more pressure than ever on 
CBC/RadioCanada to ensure its relevance to the Canadian public" (A Space for Us All, p.8). Part of this increased pressure on the $\mathrm{CBC}$ and narrowing space for Canadian content is that these companies are consuming more Canadian ad-dollars, and thereby limiting the available revenue for all of Canadian media, and the platforms do so while generally skirting the regulations essential to a functional Canadian media system. As a result, the plan is to serve Canadians by 2020 and beyond in that same environment, and in doing so Taylor says that it creates a system that devalues cable and OTA services in favour of creating "its online presence to fulfil its mandate and create a 'public space' for Canadians” (Taylor, p.350).

The documents have a five-point strategic framework to describe the main changes to CBC services (p.9). First and arguably most significant change in function is the shift from "Broad to Focused." It is most significant because it is what the document calls the "heart of the plan" wherein content and programming priorities are flipped, i.e. from the general distributions of conventional to the targeted distribution of digital, or from a "traditional approach to mobile first" (p.14). The second change, Conventional to Digital, compliments its focused approach by emphasizing the digital methods to be more relevant to Canada, yet the change includes that it is contingent with "audience behaviour and technological advances." Third, is "Producer to Multi-Platform Broadcaster" which "shifts energy and resources from production to being a modern broadcaster." What a 'modern broadcaster' means here is curiously vague, but when it is taken together with the rest of the changes it suggests that "inhouse productions," i.e., productions broadcasted by $\mathrm{CBC}$ are produced by $\mathrm{CBC}$ in-line with its mandate, will wither away under this strategy. Rowland (2015) agrees this is indeed what is happening as the strategy is leading to more "outsourcing to private producers" (p.13). Fourth, "Fixed to Flexible" focuses on shedding resources by "letting go of infrastructure, systems, and process that are less necessary in today's world." Instead, the direction sought is "embracing flexibility, scalability, agility, simplicity, and partnership" which suggest given the shedding of 
resources and infrastructure that CBC's flexibility will be dependent on digital networks to accomplish its new goals. The final change is "Cost Cutting to Financial Stability," which promises an end to historical patterns of service reductions, despite the irony resource reductions the plan enables. Overall, the strategy places a higher degree of CBC's success on how it performs digital environment because the thrust of changes in the plan "intends to put more focus on digital, mobile and social media, as a means of connecting Canadians with their public broadcaster and with each other (p.14).

For Taylor (2016), the argument that digitization is demanding this type of change in priorities unjustified, and the consequences are significant to the public sphere. As the most significant document for what PSM looks like in Canada, it begins CBC's entrance into PSB 3.0 with significant accessibility problems. Citing a 2013 Canadian Television Bureau study, Taylor finds that $94 \%$ of Canadians are connected to a broadcast distributor through cable or by OTA signals, and, surprisingly, in 2013 the numbers were rising (Ibid, p.358). Conversely, Taylor finds only $5 \%$ of people exclusively receive their news and other media from mobile devices (Ibid). This data maps onto more contemporary data cited previously about global trends in technological diversity. Moreover, recent Canadian media monitoring data does not show radical shifts either. A 2018 Numeris overview on Canadian media monitoring found that ( similar to the conventional subscriber rate of 2013) conventional television still reaches $93 \%$ of Canadians, and conventional broadcasting still reaches $88 \%$ of those ages $18-34$ weekly (Numeris: Audience Measurement in Canada 2018, 21). Based on these numbers, if CBC was concerned in strengthening increased access to its programming then its strategy should also emphasize provisions for conventional platforms. Yet it is projected that the strategy will cost the jobs of 1500 employees over 5 years from conventional platform positions (Rowland 2015, p.13). At the same time, the document seems to acknowledge the continuing importance of conventional broadcasting, by highlighting how Canada has "the largest legacy broadcasting 
infrastructure in the world" and that television consumption in has risen from "23 to 28 hours a week" over the past decade (p.6), and yet the mood at the CBC workplace post-ASFUA expresses a confusion of where and how $\mathrm{CBC}$ ought to deliver its programming.

In 2017 journalist Tom Jokinen investigated for The Walrus magazine how new digital priorities are influencing $\mathrm{CBC}$ employees, their decisions, and their goals while at work. "If we were starting over," then-president and CEO Hubert Lacroix said to Jokinen, "the smart money would invest everything into digital." The smart money investments would be put into, presumably, platforms like Facebook Live, which came into existence in 2016, and since 2017 according to one CBC employee it has become "an integral part of our assignment." This sentiment contradicts both the digital policy's acknowledgement of conventional broadcasting strength and that its approach to digital is one that is measured or "in line with audience behaviour" (p.9). So, at the core of what Jokinen identifies about CBC, much like Taylor, is a misread of technological evolution. Jokinen goes on to say that "You only have to look at the Toronto Star's experiment with creating a tablet edition of its newspaper to see how the rush to digital can end up being a colossal, expensive, and embarrassing disaster."

For the Toronto Star, one of Canada's leading private news media sources, it could not pull off a similar digital switch that A Space for Us All is building and has quickly cancelled digital-mobile investments. The Star was responding to the same cultural impulse the CBC describes in the policy, and that impulse appears to exaggerate how drastically different technological use is. For instance, policy appears to exaggerate the future it sees the CBC occupying which is one where media "will be sewn into" your clothing (p.1). No doubt that type of media will arrive but is this effective and useful for informing and serving a wide range of Canadians? Taylor calls this rhetoric influencing CBC policies as mistaking "technological evolution for technological revolution" (Taylor 2017). Overall, these types of media policy decision making are symptomatic of Jokinen's summation of A Space for Us All, wherein he 
cites media studies professor Jeffrey Dvorkin who says that "When media organizations lose sight of their purpose, they embrace technology without really understanding what it is" (Jokinen 2017).

A media organization that ostensibly understands its purpose, such as the $\mathrm{BBC}$, has a better alternative. Emden and Midgley (2012) say that "BBC has pursued the opportunities afforded by digital media at several complementary levels" from digital television and radio networks in addition to conventional linear platforms, which they say, "demonstrates an awareness of the need to plan subtly the complementarity between services, essential in an age of convergence" (p.131). Today there is not only continued popular demand for conventional broadcasting, but as early as 2012 BBC had already begun conceptualizing conventional broadcasting through a public service lens as digital adoption ascends. Moreover, in the CBC's case, it would be essential for it to consider conventional broadcasting as a public service even as it maintains audience retention, because as ad dollars shift increasingly online it may incentivize private broadcasters to migrate significantly away from conventional areas. The Thunder Bay example is relevant here: if private media finds no profitable value in being involved in those areas in television or radio, then it is incumbent on the $\mathrm{CBC}$ to ensure it has sufficient conventional resources in those areas to ensure the wide breadth of inclusion in the public sphere for those regionally marginalized in Canada.

Similarly, Taylor identifies how so far there is not much consideration of balancing conventional and with digital distribution, and the effects of which are especially significant to the public sphere. Taylor found that the 2011 Canadian leaders' debates were carried by the major cable broadcasters and "drew over 10 million viewers" (p. 359), or nearly a third of Canadians. However, in the 2015 election, after A Space for Us All and similar policies from other broadcast networks arrived, "the most watched debate of 2015 drew roughly 3.8 million viewers" because broadcasters decided to distribute debates only through digital sources (Ibid). 
As a result, "The overwhelming majority of English Canadians never saw a leader's debate in the 2015 election, though the debates were accessible to everyone online" (Ibid). Here Taylor picks up on a feature that appears to be defining the continued function conventional broadcasting will have in the digital era as digital adoption become more standard. The lack of general viewership despite ample opportunity speaks to what Burri (2015) sees as an issue endemic to digital communication: the programming is accessible, but audiences are not congregating. She cites Clay Shirky to explain that "It's not information overload. It's filter failure" (Shirky in Burri, p.164). While audiences may migrate more significantly to digital technologies, the oversaturation of channels and information in digital presents suggest that users will not congregate around programs like they do through television, OTA, or radio, which is feature writers like Scannell attribute to the public sphere connection PSBs have had. Therefore, what Taylor is ultimately depicting about PSB 3.0 in Canada is that CBC is contributing to the filtering market failure brought on by digital platforms which essential news and democratic affairs like election debates.

At a recent hearing on this matter, Taylor summarized to industry regulators what government should consider as it develops strategies for the media environment in the digital age. After all, it would be fiscally favourable to only give public funds to the $\mathrm{CBC}$ and private media insofar as they are not "wasted" by broadcasters invested in conventional areas. After citing the resilient viewership of conventional subscribers in Canada he concluded to regulators that "The online world has not caught up to the mass viewership of traditional broadcasting" and thus "there is a sustained role of broadcasting within democracy" (Taylor in Nerenberg 2018). Overall Taylor's analysis about CBC in the digital space sheds light both on the continued relevance of conventional technology in Canada but also its relationship to democracy in a way digital technology do not appear to be capable of.

\section{How CBC Policies enhance the Canadian public sphere}




\section{Subaltern Publics in PSB 3.0}

The CBC's guiding digital policy is not all doom and gloom, however, and there are aspects that ought to be maintained as more policies come to update A Space for Us All. One thing the policy does to enhance the public sphere is its targeting of marginalized peoples and giving amplification to issues in important ways that are essential for one of the foremost social cohesion issues in Canada, Indigenous reconciliation. With a digital emphasis in its resource allocations, there are new online spaces like CBC Indigenous and Espaces Autochtones websites which "are designed as places where all Canadians can learn and exchange with one another on Indigenous issues" (MacGuire and Cormier, 2017). Clearly the plans for motivating public sphere participation are more than just rhetoric since there is greater inclusion of minority publics like indigenous voices, and at a time when Canada is beginning its reconciliation efforts with colonialism.

The CBC playing a central role in this national effort to socially address colonialism and its ongoing consequences is essential if efforts of reconciliation are to garner the widest reach of Canadians across the country. However, while this is an important use of digital technology for PSMs, there is at least one problem it has with social cohesion goals and reconciliation itself. Management argues that it must not increase resources or attention to conventional areas because younger audiences are using digital and that "television and radio, platforms primarily attract an older audience" (Ibid). For that reason, management adds that it does not agree that resources should be reduced in digital spaces. Yet, few are calling for a reduced presence in the online space, but if elevating consciousness of the plight of counterpublics in Canada is to have widespread social cohesion outcomes, then there should be an emphasis on providing information and education on Indigenous issues to older audiences who are more likely to consume $\mathrm{CBC}$ on television or radio. Moreover, it is likelier that older generations have a weaker relationship or engagement with the movement of Indigenous and colonial 
reconciliation compared to younger Canadians, given that Canadian youth today are socialized into reconciliation programs in their school curriculums. Therefore, while new digital services that amplify Indigenous counterpublics voices are important, it is difficult to consider it a significant strategy for reconciliation if it does not target the whole of Canada for which CBC is capable of. In other words, there should be push back about the 'either-or' agenda in distribution of programs intended for social cohesion, and instead focus on a universalist approach to issues like reconciliation.

\section{Countering Commercial Enclosure}

The most essential part of CBC's digital era vision does not come from A Space for Us All, but rather a policy that is intended to update it. For context: in 2015 a new federal government arrived a year after the plan was proposed, and the government ran on a promise to restore the funding $\mathrm{CBC}$ had lost from the previous government. The new government's receptivity to the $\mathrm{CBC}$ presented the broadcaster with the opportunity to argue for a meaningful plan for PSB 3.0. As a result, A Creative Canada: Strengthening Canadian Culture In Digital World (ACA) arrived in 2016, and when taken together it poses a greater proposal for PSB 3.0 in Canada than relying on A Space for Us All alone. More importantly, the document is persuasive in demonstrating the need for the government to reconsider the purpose of the CBC and how its values can strengthen media in Canada.

As outlined earlier, there are troubling developments both political and economic that suggest a major intervention is required if there is be a continued presence of PSB in Canada. ACA is that formal call for the major interventional and it does so by highlighting that

The shift of advertising dollars away from traditional television services (particularly conventional television services) to the Internet and wireless services is negatively impacting the Corporation's financial strength. $\mathrm{CBC}$ is thus facing challenges funding programs, let alone new ones (A Creative Canada, 2016).

As a result, at the heart of the plan is to secure increased and fixed funding -- about an extra $\$ 420 \mathrm{M}$, or about $\$ 46$ per taxpayer -- to allow the organization to be ad-free (A Creative Canada, 
5). In addition to wavering market ad dollars, the plan also demonstrates that despite recent government refundings, CBC's budget will not have any positive net benefit due to inflation by 2022 (p. 16). Therefore, despite government refunding, CBC stands to be in the same fiscal place it was in 2014 in a few short years, but the fiscal situation could be much more dire should there be a continued monopoly presence in Canadian digital media, or if a new government reduces CBC's appropriations. If A Space for Us All is indeed what Taylor calls a "cost cutting strategy" drawn from declining budget revenue (p.357), then ACA can be thought of a strategy anticipating a significant decline in market revenue drawn from conventional spaces.

It appears that the untenable contradictions in CBC's funding structure is at the core of CBC priorities. A Creative Canada is the document that campaigns for viable and sustainable strategy for PSB 3.0 in Canada by encouraging government to see the benefits of divorcing CBC from the market, create increased and stable funding, and ultimately generating an ideal PSB system. It argues so out of the economic and cultural externalities that an ad-free CBC would bring to Canada. The document demonstrates that not only is it CBC's mandate and focus on "championing" Canadian content, but if it received the extra $\$ 420 \mathrm{M}$, it would also translate into 7,200 more Canadians jobs (p.30). Moreover, by leaving the adverting market $\$ 158 \mathrm{M}$ would migrate to the private sector (p.5), which Lacroix has said in a press release in 2017 would also allow $\mathrm{CBC}$ to "focus on its public service mandate and become a better supporter of Canadian culture" (Lacroix, 2017). This all suggests that there is increased desire, perhaps out of existential pressure, for $\mathrm{CBC}$ to break from the market completely, and that in doing so it would allow CBC to fulfill its mandated obligations more effectively.

The plan is ultimately asking for government to recognize how Canadian media, the public sphere it upholds, and thus Canadian democracy, is witnessing a crisis. The conventional audiences are indeed sustaining in the digital era, but its monetary value is not. Migration to digital is happening but not in a general or filtered way essential for serving the public sphere. 
All of these problems make the public service commitments essential to an equal and accessible public sphere more difficult. To make matters worse, the advertising money to be made in the Canadian digital environment is not what it should be because of the monopolizing power of Google and Facebook. The most logical route from $\mathrm{CBC}$ management's point of view is to demonstrate that despite this chaos in Canadian media markets, a stabilizing solution is possible by way of being "all in" for PSB in Canada. The end result of A Creative Canada, although to a smaller scale, is a financial structure that resembles BBC whereby its funding is substantial, fixed, and long term.

Unfortunately, however, there has been no formal government response to this proposal.

\section{How CBC's PSB 3.0 hinders the Canadian public sphere}

\section{Approaching but Rejecting The Digital Commons}

There have been other proposals as to what the CBC that it could do on its own to help settle some disruption across Canadian media. In a study on Canadian news media, The Shattered Mirror: News, Democracy, and Trust in the Digital Age, one of the proposals is to transform CBC News into something like a 'Media Safety Net' for financially insolvent and unprofitable media. One interesting recommendation it has for $\mathrm{CBC}$ News is to place it under a "Creative Commons licence" to allow for free re-publishability of CBC News by other news outlets (p.90).

This proposal is interesting and would enhance the Canadian public sphere because it represents a policy that operationalizes themes of the digital commons concept. It would fulfil digital commons goals by sharing resources and amplifying voices of other media by allowing them to use CBC News content relevant to their region, and ostensibly emphasize public service journalism initiatives because it would make $\mathrm{CBC}$ a "universal public provider of quality journalism." However, it was rejected by $\mathrm{CBC}$ because the proposal on grounds that the 
proposal is irrelevant because management feels it already is a universal public provider of quality journalism (News and Democracy in the Digital Age, 2017). Although, it appears this rejection is a misread of what the proposal is genuinely calling for. It is not calling for CBC management to improve its service specifically, but to share its news in ways that would allow for smaller media in Canada to freely reproduce $\mathrm{CBC}$ content relevant to its region.

The proposal would benefit CBC's role in the public sphere in two significant ways. First, it would put $\mathrm{CBC}$ at the centre of salvaging media diversity, and at no extra cost, which strengthens its mandated obligation to serve regional needs. Second, it echoes a theme of the digital commons by placing $\mathrm{CBC}$ at the heart of public interest institutions by using CBC's local coverage as a method to facilitate more collaboration between civic institutions. A benefit of this proposal would also allow for waning local journals to divert capital it would save by using relevant $\mathrm{CBC}$ content into use through more investigative and public service journalism. Overall this policy proposal is an interesting way to colour what is meant by placing PSBs at the centre of a broader project of converging the civic public interest values. However, part of the pushback from the $\mathrm{CBC}$ about this proposal is probably because the proposal suggests $\mathrm{CBC}$ directly offer content and resources to its competitors. That is why for CBC to be at the heart of any digital commons strategy that links civic public interest institutions it should be coupled with the ad-free proposal drawn from A Creative Canada. In other words, this proposal from the Shattered Mirror, like A Creative Canada, must be reconsidered when and if CBC considers what in-house strategies it is capable of doing to enhance the whole of media in Canada - which would likely only be possible with the broadcaster becoming ad-free.

\section{Diluting CBC's Public Sphere Contribution}

Given that the strategy relies more on a digital and mobile presence and partnership with digital organizations to fulfill strategic goals of targeted content delivery, there is greater reliance on with likes of Facebook and similar platforms. Social media platforms are the primary 
ways in which a Broad to Focused can be developed because delivering content to specific audiences are the main offering platforms like Facebook have to make business. This focused approach, which Taylor terms 'post-broadcasting,' is why he mentions a disconnect between $\mathrm{CBC}$ and its public sphere relationship because it focuses on specific, narrow and fragmented publics, which is in contrast to the "varied messages to a general audience" (p.352) traditional definition of broadcasting that Taylor finds essential to the public sphere. One can also find that this definition of broadcasting contributes the universalist distribution of programming that Scannell to justify that PSBs are essential to public sphere theory. This begs one to ask then: what about the post-broadcasting, or narrowcasting, approach enabled by the likes of Facebook, disrupts the relationship between $\mathrm{CBC}$ and the public sphere?

A recent analysis about Facebook's effects to democracy and media from Siva Vaidhyanathan offers insight here. He writes that "Over time Facebook not only rewards the users with items that are likely to generate the most markers of engagement (clicks, likes, comments, shares) but also learns to tailor the News Feed of every Facebook profile." As a result, Facebook's modus operandi is to "segregate the public into cultural and political universes. It's the core of Facebook." (p.88). Here there a greater explanation to why Tufecki speaks of the public sphere in the digital age as frayed and incoherent, and it suggests that CBC's attachment to Facebook will worsen fragmentation in public sphere engagement, which is already stratified by the platform preferences to curate content to such as the wealthy or educated. In other words, by focusing on narrow delivery of programming through platforms like Facebook, $\mathrm{CBC}$ is allying itself with the foremost driver of a type of fragmentation that differentiate access to the public sphere and who Facebook decides should be included in the public sphere.

There are other concerns Vaidyanathan identifies for PSMs like CBC about Facebook, and these concerns demonstrate a gap between what the broadcaster and the platform value. 
That is to say, Facebook operates firmly in the market model of public interest and has little incentive or regulation to enforce the civic model. That is because Facebook's fundamentally operates on the application of the market public interest that targets only the "relevant" programming or content to users, but its definition of relevant does not have any bearing, Vaidyanathan says, "on the helpful, the enlightening, the moral, the educational, or the true" (p.90); in other words, how social media platforms like Facebook define relevance has no significant association with promoting the mandates of public broadcasters. Instead, what it does have association with is what is most monetizable like content that has the ability to 'viral' like memes or short amusing videos; or in other words, the short, emotional, and visually stimulating types of content. While operating on Facebook, $\mathrm{CBC}$ and most legacy media are inherently disadvantaged in maintaining their standards and ethical practices compared to digital-native sites that have no legal binding to operate one way or another; therefore, one can expect, especially if conventional sources of revenue continue to fall, that CBC's operations on the digital platform will be susceptible to replicating Facebook's values in media creation in order to maintain its revenue stream.

This is a logical conclusion because Facebook is primarily an advertising company, and the largest one at that. While Facebook may not have a direct role in the media creation in the way conventional broadcasters and advertisers do, it is still indirectly influential on media like CBC the same way all advertisers are influential on media. Rowland (2015) writes that "programs paid for by advertisers inevitably have their content shaped by the business imperative of broadening the audience base, and by the values inherent in consumer culture" (p.71). So, while management may publicly suggest CBC abstain from the behaviour seen replete across media operating on Facebook (MacGuire and Cormier 2017), the logic Rowland provides about ad-funded material shaping programming and culture of media is why one former CBC employee quit the journalism industry all together. 
In the Shattered Mirror, there is analysis and discussion drawn from the experience of former $\mathrm{CBC}$ producer Chris Lane, who believes the switch to digital-first has been counterproductive for CBC. 'It's not a business case that's working, in my view. Our 'presence' and 'reach' may be wider, but it's not funding, expanding or even retrenching our journalistic obligations" Lane says (p.22), and with good reason. Audiences brought on from the digital pivot are not financially stabilizing given that CBC only makes about $\$ 25$ million annually from digital ads (p.75), and that the pivot has been journalistically inappropriate because as "clicks increased" producers and reporters were laid off in favour of social media co-ordinators (Ibid). This change in the character of workers at CBC News, Lane says, contributed to workplace language shift from creating "stories" to creating "content," which for him "are not interchangeable" (p.22). His summation of the consequences of the digital shift are that "In the quest to make declining traditional media more relevant, I think we made it more disposable" (Ibid). Overall, Lane's experience at CBC during while A Space for Us All reformulates goals and practices at $\mathrm{CBC}$ demonstrates a concerning growing problem whereby $\mathrm{CBC}$ resource and content are becoming worryingly influenced by the values of Facebook in ways that reflect its mandate, and it hints at broader problems of a narrowing gap of independence from CBC priorities and those of Facebook.

\section{The Erosion of Independence in the Digital Era}

There are a few case studies that heavily involve the direction of A Space for Us All, and they provide concrete examples of how the policy is a hinderance to the Canadian public sphere. The first example came in November 2018 when journalist Jesse Hirsh was on CBC's radio program Metro Morning to critically discuss Facebook. He offered his thoughts on the platform in light of a New York Times column that reported the platform knew about Russian interference in the 2016 US election but chose to do nothing about it. Similarly, Facebook has been linked with anti-democratic and anti-social accusations lately; the most famous examples 
include Facebook playing a role in the 2016 US elections but also the Brexit referendum that same year in Britain through data-selling of citizen data and amplifying and facilitating propaganda proliferation. In Sri Lankan officials singled out Facebook for platforming antiMuslim propaganda that left three people dead in riots in Sri Lanka (Thompson, Feburary 19 2018). Similarly, the UN has called out Facebook for facilitating propaganda that likely led to the genocide of minorities in Myanmar (Ibid). Justifiably then, it has grown clear for Hirsh that Facebook is completely divorced from the values and goals of democratic institutions like the CBC.

Hirsh believes more needs to be done besides hoping for adequate state regulation or for the company correct its own behaviour, so instead he suggests action should begin in the public sphere with the help of the CBC. His appearance on the program concluded with this call-toaction to address the CBC's relationship to Facebook:

"Why does CBC trust Facebook? Why does every CBC employee tell their audience to 'Like' CBC on Facebook? Why do the people at $\mathrm{CBC}$ mandate that $\mathrm{CBC}$ personnel promote Facebook? Why does CBC continue to engage in a commercial relationship with Facebook, now that it's clear that Facebook is a threat to democracy, and the CBC as a public broadcaster should be strengthening democracy?" (Hirsh in Canadaland, Nov. 2018).

His segment was thereafter removed from the CBC's archives (although other media outlets salvaged the audio of the program). The CBC ombudsman justified the removal by appealing to how Hirsh failed to live up to the corporation's journalistic standards. Hirsh soon after appeared on a podcast from the alternative media Canadaland to explain the event, his actions, and more on his thoughts about the CBC and Facebook.

Hirsh disagrees with management's journalistic standards claim, and even says it is hypocritical. Hirsh has criticized Facebook constantly in his two decades as a reporter at the CBC; however, before 2018's the privacy breach of over 50 million of Facebook users for political purposes, each time Hirsh criticized Facebook the platform would then complain to $\mathrm{CBC}$ and management would scrutinize Hirsh. In every instance, Hirsh says, management never defended him from Facebook. More troublingly, on one occasion according to Hirsh, CBC 
informed Facebook about the arguments in Hirsh's column so that Facebook could prepare a rebuttal before the column's publishing (Ibid).

This case signals how platforms like Facebook can corrode the independence of organization like $\mathrm{CBC}$ in ways more intimate ways than might be imagined. Hirsh is supposed to be an adversarial critic of Facebook, yet there is evidence of increased limitations of how critical he can be given that Facebook is central to CBC's digital strategy. This is hypocritical, Hirsh says, since CBC News will continue to criticize Facebook and inform Canadians citizens of how their Facebook data is sold for anti-democratic activity, how their everyday activity is spied upon, and so on. Yet all the while, there will not be discussion about the ways in CBC helps enable Facebook's anti-democratic activity, namely by “making them richer” Hirsh says, all the while Facebook actively corrodes democratic values and institutions internationally.

This example demonstrates how the policies that attach $\mathrm{CBC}$ closely to Facebook are eating away at CBC's independence. Independence is one the qualities Rowland cites as most essential and distinctive of public broadcasters, and he also highlights a particular brand of independence that is relevant here: moral independence. Rowland references the university as the model independence PSB aspire to because they too must be public "be morally independent, giving it licence to reflect, criticize, and explore the values of governments, commercial interests, and the communities to which it broadcasts" (Ibid, 71). This is precisely what Hirsh is attempting to do, and not rather calling for an end of its relationship to Facebook - although CBC would not be the first big organization to leave Facebook. In 2018 the lifestyle, current affairs, and entertainment magazine Playboy ended all its Facebook activity and the page of the Tesla car company left Facebook completely because of the platform's privacy scandals (Thompson and Vogelstein, March 20, 2018). Hirsh is rather encouraging CBC to publicly discuss its connections to Facebook, and according to Rowland, reflexive analysis of CBC about its own actions is central to PSB values. Without such an effort to scrutinize its 
waning independence, Hirsh's debrief on Canadaland demonstrates that new digital policies are makes some reporting, especially on technology companies, fruitless, and it capitulates the viability of public broadcasting values, like democracy, to the interests of anti-democratic organizations like Facebook.

Finally, there are also few specific ways this case study negatively affects the public sphere as outlined by Moe (2008). There is a lack of equality wherein Hirsh and his topic of $\mathrm{CBC}$ independence from Facebook is not given free expression or being meaningfully listened to; there is evidence of constraint against him and the topic CBC's relationship to Facebook; additionally, the topic presents a lack of openness, where there is not a free flow of topics that are integral to the public sphere itself. Overall, what this suggests is that the most acute problem of A Space for Us All may not be its targeting of indistinct and smaller audiences on digital over conventional audiences, but rather (if and when) audience shift dominantly to digital methods of media engagement, the plan leaves the CBC subordinate to the will and decisions of actors like Facebook who have diametric goals with the $\mathrm{CBC}$ but still have influence over both content and its delivery. It evidently already has and given management's dismissal of Hirsh's story and its overall removal from CBC archives, the public broadcaster's independence from Facebook is problem likely to continue and compound in the future.

\section{Narrowing Political Citizenships in Pursuit of Relevance}

Lastly, there is a second example of $\mathrm{CBC}$ continuing to disenfranchise citizens from democratic engagement due to its prioritizing of digital over conventional audiences. Included in A Space for Us All are acknowledgments that digital directions will be contingent on developments in Canadian media habits (p. 13), so one would expect a nuanced deployment of a digital-first strategy that does not compromise CBC's commitment to the serving Canadians. Yet recently, citing the direction of A Space for Us All, CBC management chose to use a predominantly digital distribution of programming which shielded many Canadians from 
engaging in important democratic activity of the 2018 municipal elections in Ontario through conventional means.

On October 18th CBC announced that it would not carry live the October 22nd municipal elections in Ontario on television networks. Instead, the broadcaster opted for updating events online once results rolled in. The reason provided for foregoing coverage on television networks was because of advertising commitments for programming scheduled in the hours after voting finished (Mathieu, Oct. 17, 2018). CBC chose to continue with the scheduled 8 pm broadcast of Murdoch Mysteries and the 9 pm broadcast Frankie Drake Mysteries 9 pm in place essential civic public interest programming like municipal elections. Despite this shortcoming, $\mathrm{CBC}$ did live updates on its Facebook pages for the local elections, but live journalistic coverage of election results in regional areas would begin on conventional networks until $11 \mathrm{pm}$.

This may suggest that $\mathrm{CBC}$ had less financial wiggle room in 2018 to emphasize important civic public interest decision making like robustly covering municipal democracy. There was plenty reason for $\mathrm{CBC}$ to broadcast on television the election in real-time with journalistic oversight, but due to its lack of nuanced adherence to the digital-first strategy there are signs that the digital strategy is significantly damaging the broadcaster's cachet as a central public sphere element. This sentiment is shared by CBC workers.

In a letter to management, newsroom staff at $\mathrm{CBC}$ Ottawa criticized the public broadcaster's decision to not air live coverage elections on television. The decision they said, will do "long-term damage to the CBC and will inevitably erode our standing with our audience and Canadians at large, [because] many of our viewers in the Ottawa region, who either cannot afford internet access, don't have ready access to it, or who are not inclined to watch election newscasts online, will not be able to watch live coverage of the local election results provided by their public broadcaster" (Houpt, Oct. 22 2018). Noting that the digital-first strategy of A 
Space for Us All is dictating these decisions, members of the newsroom told The Globe and Mail that conventional television in their area still accumulates more audiences for events like elections (Ibid). Moreover, it suggests A Space for Us All's claims of measured or incrementalism to a digital-first strategy is showing little sign of serving the public sphere appropriately. That is why CBC-Ottawa reporter said

"We still need to be where people are, not just where we predict or hope they will eventually be. Could we fathom not airing a federal or provincial election live on TV in 2019? If not, then why is it acceptable to jettison our local TV coverage in 2018? Now that the precedent has been set, will this become the new normal for local television? The decision smacks of a kind of egregious elitism" (Houpt, Oct. 22 2018).

In response, management deferred to the $\mathrm{CBC}$ digital policy as the rationale for all decisions by saying "We have been working under a digital-first strategy for nearly five years and that's the lens we use when we're making difficult decisions" (Ibid). This suggests that there is not much flexibility to manoeuvre digital priorities to serve Canadians in the most efficient and accessible ways. Taken together with Hirsh's case, CBC's coverage of local Ontario election cements the notion that there is a culture within the CBC that defers to the logics and goals of A Space for Us All which go on to inhibit its mandate and therefore its commitment and contribution to the Canadian public sphere.

\section{Improving PSB 3.0 in Canada}

Based on this discussion it appears that A Space for Us All fails to enhance the CBC's position in the Canadian public sphere. The proposal has significant issues in maintaining the $\mathrm{CBC}$ as an essential element of the Canadian public sphere, i.e. narrowcasting creating new stratifications in public sphere participation, smaller demographic distributions, and unhelpful attachment to private and anti-democratic platforms. However, there is significant effort on behalf of the $\mathrm{CBC}$ and government that provides the basis for new a more amicable digital future that adequately caters to fundamental problems in the public sphere. The need to salvage the media environment for the public sphere is not lost on the $\mathrm{CBC}$ nor government, but the political will has yet to arrive. 
If the political will arrives, then these are the priorities that should be considered for strengthening Canada's PSB and the public sphere it serves. A first priority thereafter would be to correct accessibility issues. A demonstrated by the Ontario elections example and Taylor's federal election example, there is a culture of stratification currently affecting $\mathrm{CBC}$ and the Canadian public sphere on the basis of technological access and use. Therefore, CBC must emphasize current failures in accessibility and consider the BBC model which conceptualizes conventional platforms as a growing public service initiative in itself. Moreover, improving resources in conventional areas could also strengthen independence from digital-native companies like Facebook, like those found through the narrowcasting of CBC programming to smaller and stratified publics, or the unsavoury influence Hirsh says Facebook has over CBC's mandate and journalistic integrity.

Similarly, the second priority should consider how its informing and educating roles can be mobilized towards more positive socially cohesive ends for the public sphere. A media literacy initiative should emphasize critical digital media curriculums like the one offered by Jakubowicz. This should include lessons like critically judging truth in journalism, how to navigate trustworthy sites, what the consequences of sensationalist or propagandistic media can be and have been, and more. Operationalizing such an initiative may model The European Union's 'Europeana' which is a digital platform CBC could emulate. According to Burri (2015), one of the many services it offers are programs concerned with "digital literacy skills, so that users can make the best of both digital affordance and the content available" (Burri, 216).

Such an initiative brings to mind BBC's relationship to Open University, which offers a range of free programs accessible to all and shares resources and talents with the BBC. Where Open University offers a range of fields to study from for free, a CBC venture could focus singularly on offering critical media literacy skills that are tailored and developed by a range of academics within the field to build and teach programs freely accessible through CBC web and 
mobile platforms. The effect of such media literacy programming could help reduce the stratifications that exist in media engagement. Generations young and old that have significantly different relationships to digital media, and each would benefit from programs that can bring a sense of equality in how the public understands and uses media in the digital age. One could anticipate, for instance, such an initiative would put PSM at the heart of equalizing the public sphere. However, proposals that tackle accessibility, independence, and literacies are contingent on a whole new funding system for the $\mathrm{CBC}$ that allows it to revitalize the civic model of public interest. A new funding model would resemble proposals like A Creative Canada, where there is a substantial parliamentary appropriation over a fixed term to strengthen independence from political and economic disruptions, and ideally makes CBC fully detached from the ad-market, or partially detached from either digital or conventional areas. From that starting point, new ambitious proposals must be considered in order to fashion an environment for PSB in Canada that is as trailblazing for Canadian media as the original creation of CBC was. As a result, with the advent of sufficient funding and appropriate structuring within Canadian media, a project of constructing a Canadian digital commons with the $\mathrm{CBC}$ at its centre can come into focus.

\section{Strategies for the CBC's The Digital Commons}

Undoubtedly, for $\mathrm{CBC}$ to participate in a digital commons initiative, it will require ambitious strategies. However, it should be noted that the successes and innovations of PSB 1.0 were ambitious ideas and practices for their time too like universalism, minimizing sensationalism, and other policies that were directly concerned with a declining public sphere. Moreover, the $\mathrm{CBC}$ should have similar motivations for ambitious strategies due to the similar decline in the public sphere today as when PSBs were invented. Accordingly, one novel initiative $\mathrm{CBC}$ could employ to participate in the digital commons is by applying the concept to counter particular digital disruptors of the public sphere, namely social media platforms. Murdock's 2004 concept precedes the growth of mobile and mainstream digital technologies, 
but their introduction provides a way to operationalize what he was envisioning by fashioning PSBs as the central node in the network of a public sector convergence. Therefore, CBC should participate in a digital commons strategy by providing something akin to a public service media application.

Firstly, political economist Nick Srnicek offers analysis why the structure of private social media are "often at odds with the requirements of a functional public sphere." It is imperative to organize public ownership surrounding social media platforms because of the standard of communication these platforms are having on the public sphere. The type of communication the likes of Facebook and Twitter are standardizing by explaining that

\begin{abstract}
One of the major differences between discussion on the internet and discussion elsewhere is that there is often an imagined audience online. What happens is that you end up writing not to learn something, nor to necessarily engage with an idea, nor to question something or even question yourself, but instead to perform for this audience. This is extremely detrimental to any type of proper discussion - it leads to a game of trying to appease this imagined audience, with likes and RTs being the most salient metric of success. For that reason, I don't think Facebook, let alone Twitter, lend themselves to meaningful discussion (Beyond Endless Winter: An Interview with Nick Srnicek)
\end{abstract}

While Twitter ostensibly does provide space for meaningful engagement, the company is "instead concentrated on trying to generate more attention on their service, attracting more advertisers, and incentivizing more superficial engagements" like content optimized for search engine pick-ups, or the proliferation of content farms, or clickbait, to "fake news." Therefore, the status quo for privately organized social platforms are inherently disruptive both in the type of discussion they elicit from users and the type of engagements the platforms most seek to foster are counterproductive to the public sphere.

Alternatively, Srnicek favours nationalizing platforms such as Twitter and Facebook because they "natural monopolies like utilities and railways that enjoy huge economies of scale and serve the common good have been prime candidates for public ownership" (Srnicek, August 2017). Nationalizing these platforms is becoming more justifiable as the dysfunctional effects to our social relations, politics, culture, media and democracy in the digital era grow alongside the profit of a few corporations that benefit from these problems and exacerbate it. A 
nationalizing project would make profits fund insolvent newsrooms, public projects, and overall retrench social media platform within democratic norms for which they are avoiding and, in some cases, actively attacking (Ibid). As a result, a nationalizing project that puts what he calls the "infrastructure of 21 st-century society" (Ibid) into public hands would ensure the communication technologies that will characterize PSB 3.0 are firmly within the civic model of public interest. Therefore, one can see how replacing market domination on the flow of communication in the public sphere in the digital era with a national, public alternative there is an opportunity to organize the conditions that essential for vibrant, pluralistic civic discourse and cultural exchange uncompromised by profit motives and interests of foreign organizations .

More developed policy proposals for a public service social media has been put forth by British Labour Party leader Jeremy Corbyn, which is also explicitly concerned with revitalizing the public sphere through digital direct-democracy initiatives. "The public realm" Corbyn says “doesn't have to sit back and watch as a few mega tech corporations hoover up digital rights, assets and ultimately our money" (Waterson 2018). The proposed 'sister company' to the BBC, British Digital Corporation, would be used to create programming, accessible archive material drawn from the public sector, and perhaps most interestingly "operate a social networking arm that could play a role in direct democracy" (Ibid). The voting system would also play a role in what BDC programs are by giving citizens logins to vote on what the corporation creates (Ibid). Overall the idea is centred on providing accounts and access to a platform for all citizens for engagement in a digital direct democracy for matters political, social, and cultural.

Another feature that must be considered that has not been touched upon about what a public service media should consider is what universalizing accessibility would mean. Were the platform to be firmly a public service, data charges would be unencumbered it if a user is unconnected or unable to afford Wi-Fi. Achieving 'zero-ratings' on PSM services would be a difficult task, and it would require detachment from the market do not provide unfair 
advantages. As a result, the digital commons would be genuinely accessible to all with digital devices, which in turn provides a universalist public service unique to the digital age. It would also enable access to the public sphere for the most marginalized of all like the poor or perhaps homeless; or in other words, those with next to nothing to offer advertisers or businesses. In place of creating a social media platform that is optimized for advertisements and sensational, ephemeral content a public service social media could be used, for example, to promote and elevates the names and causes of organizations working within non-profit and civic institutions. With a public service social media, the most marginalized, who at least have access to digital devices, could freely access a CBC app with all its local news, its entertainment, and more importantly with its promotions of those civic and non-profit institutions that may be an enormous service to that person. This feature inaccessibility would be especially significant for widening the public sphere and could have similar effects that universalism had during PSB 1.0 for equalizing the public sphere in PSB 3.0.

These types of ambitious plans should be at the heart of CBC strategies and proposals to the government for revamping and correcting its relationship to the Canadian public sphere. Part of what makes the ambitious strategies so necessary to put forward is that it gives oxygen to the notion that governments and policymakers should be explicitly concerned with funding the civic public interest use of communication technology rather than letting markets dictate the major portion of the communication infrastructure of the public sphere in the 21st century. PSBs played the central role during the introduction of radio and television during the early to mid $20^{\text {th }}$ century, and much of the improvements within the public sphere during that time can be drawn from the emphasis placed on ensuring communication technologies were organized around the civic public interest. Today, a return to such a vision is necessary as democracies and public spheres show signs of dysfunction. Strategies like should be considered like sharing resources within Canadian media, ad-free services, zero-rating on data use of CBC digital 
content, universalizing media literacy for Canadians, or major projects like public service social media to create a distinct era of digital public media making. Any of these proposals would be a welcomed approach to tackling the growing problems within the Canadian public sphere and the PSB essential to its functionality.

In conclusion, CBC's current plans for the digital era are insufficient for properly serving the public sphere. In certain instances its plans suggest an antagonistic relationship to the public sphere by exacerbating issues of $\mathrm{CBC}$ independence from the market (namely private social media actors) and accessibility, which have in multiple cases demonstrated a deteriorating relationship to the Canadian public sphere, and the problems suggest an unwavering commitment to this status quo in 2020 and beyond. If the status quo was challenged with new iterations for PSM in Canada, then those new policies would explicitly consider a public sphere philosophy that was more in line with what the ideals that PSB 3.0 literary device calls for, which target problems in independence, literacies, independence, accessibility, and the civic public interest. None of these strategies are possible from CBC's own doing, however, without support from government which should consider how public media policy is an essential tool for stabilizing and equitizing the public sphere that Canadian democracy rests on. Attacks on democracy around the world alone should provide the government to consider funding the institutions like $\mathrm{CBC}$ whose responsibility are for strengthening democracy. This historical moment is calling out for ambitious policies, and if $\mathrm{CBC}$ and the Canadian government act on them, then $\mathrm{CBC}$ could leap closer to the most ideal media system required for the Canadian public sphere. 


\section{Bibliography}

Armstrong, R. (2010). Broadcast Policy in Canada. University of Toronto Press. Print.

Bailey, M. (2007). Rethinking Public Service broadcasting: The historical limits of publicness. Butsch, R. (Ed.), in Media and Public Spheres. Palgrave MacMillan.96108.

Balnaves, M., Donald, S. H., and Brian Shoesmith. (2008). Media Theories and Approaches: A Global Perspective. Palgrave Macmillan. Print.

Barros, S. (2015). Civic Media Functions in the Public Sphere. MIT Centre for Civic Media. https://civic.mit.edu/2015/04/08/civic-media-functions-inside-the-publicsphere-model-0/

Benhabib, S. (1992). Models of Public Space. in Calhoun, Craig, Habermas and the Public Sphere, Cambridge Mass.: MIT Press.

Boeder, P. (2005). Habermas' Heritage: The Future of the Public Sphere in the Network Society. First Monday 10(9). http://firstmonday.org/article/view/1280/1200

Brown, J. and Hirsh, J. (2018). An Issue Worth Torching Your Job Over. Canadaland. https://www.canadalandshow.com/podcast/an-issue-worth-torching-your-job-over/

Burri, M. (2015). Public Service Broadcasting 3.0: Legal Design for the Digital Present. Routledge. Print.

CBC/Radio-Canada. (2014). Strategy 2020: A Space For Us All. http://www.cbc.radiocanada.ca/_files/cbcrc/documents/explore/transforming/a-space-for-us-all-summaryv12-en.pdf

CBC/Radio-Canada. (2016). A Creative Canada: Strengthening Canadian Culture In Digital World. http://future.cbc.ca/images/acreativecanada.pdf

CBC/Radio-Canada. (2017). News, Democracy and Trust in the Digital Age: Putting Canadians First. http://www.cbc.radio-canada.ca/en/media-centre/2017/04/05a/

CBC News (Aug. 26, 2016). Tragically Hip Concert Draws Millions of TV 1

Viewers. https://www.cbc.ca/news/canada/tragically-hip-cbc-broadcast-ratings1.3730276

Chidley, J. and Turbide, D. (Sept. 30, 1996)."CBC Cuts Announced". The Canadian Encyclopedia. https://www.thecanadianencyclopedia.ca/en/article/cbc-cuts-announced Conway, K. (2009). Public service broadcasting and the failure of political representation. VelvetLight Trap, 64(64), 64-75. 
Conway, K. (2011). Everybody Says No Public Service Broadcasting and The

Failure of Translation. Kingston: McGill-Queen's UP. Print.

Conway, K. (2012). Who Is "the Public," and "What Does "the Public" Want?. in

Technology /Form: An Introduction to Media Studies. University of North Dakota Communication Program.

Dickson, J. (2016). Scheer says he would axe CBC news division. iPolitics. Retrieved 22 February 2019, from https://ipolitics.ca/2016/12/09/scheer-says-he-would-axe-cbcnews-division/

Fraser, N. (1990). Rethinking the Public Sphere: A Contribution to the Critique of Actually Existing Democracy. Social Text, (25/26), 56-80. doi:10.2307/466240

Friends of Canadian Broadcasting (2014). Change in Parliamentary Appropriation to CBC (in 2014\$).Friends.ca. https://friends.ca/explore/article/change-in-parliamentaryappropriation-to-cbc-in-2014/

Gardener, S. (2017). Public Broadcasting: Its Past and Its Future. Knight Foundation. https://knightfoundation.org/public-media-white-paper-2017-gardner

Gardener, S. (2018). A Matter of life and death: Sue Gardner on public broadcasting. https://www.cbc.ca/radio/ideas/a-matter-of-life-and-death-sue-gardner-on-publicbroadcasting-1.4701029

Gauthier, M. M. (1997). Window of opportunity: Public broadcasting, the ideal of democratic communication and the public sphere. PhD Dissertation. McGill University, Montreal, QC.

Government of Canada. (1991). The Broadcasting Act. Department of Justice.

Grbeša, M. (2003). Why if at all is the Public Sphere a Useful Concept?. Politička Misao. 40(5). p110 - 121.

Gureev, A. and Srnicek, N. (March 1 ${ }^{\text {st }}, 2018$ ). Beyond Endless Winter: An Interview with Nick Srnicek. Versobooks.com. https://www.versobooks.com/blogs/3652-beyondendless-winter-an-interview-with-nicksrnicek?fbclid=IwAR1o3jez6w2ObnMiCrvH421JaktyWMQqmg_jvffFr44svVA9bf_Z-vcmE4

Kohut, T. (2016). Thunder Bay TV stations surviving on life insurance cash, shutdowns looming. Global News. https://globalnews.ca/news/2481036/thunder-bay-tv-stationssurviving-on-life-insurance-cash-shutdowns-looming/

Habermas, J. (1989). The Structural Transformation of the Public Sphere: An Inquiry into a Category of Bourgeois Society. Trans. Thomas Burger. Cambridge, MA: MIT P, 1989. Print

Habermas, J. (2006). The Public Sphere An Encyclopedia Article.” in Media \& Culture: 
KeyWorks.

Houpt. S. (Oct. 22, 2018). CBC staff push back as broadcaster opts not to air live coverage of Ontario's municipal elections. The Globe and Mail. https://www.theglobeandmail.com/arts/television/article-staff-push-back-as-cbcottawa-opts-not-to-air-live-coverage-of

Iosifidis, P. (2011). The Public Sphere, Social Networks and Public Service Media. Information Communication and Society, 14(5), pp. 619-637. doi: 10.1080/1369118X.2010.514356

Jakubowicz, K. (2010). PSB 3.0 Reinventing European PSB. In P. Iosifidis (Ed.), Reinventing Public Service Communication: European Broadcasters and Beyond. Palgrave MacMillan. 9-17.

Jokinen, T. (August 21, 2017). Is The Sun Rising or Setting on The CBC?. The Walrus. Retrieved from: https://thewalrus.ca/is-the-sun-rising-or-setting-on-the-cbc/ Lacroix, H. (2017). News, Democracy and Trust in the Digital Age: Putting Canadians First. CBC-Radio-Canada. http://www.cbc.radio-canada.ca/en/mediacentre/2017/04/05a/centre/2017/05/18/

MacGuire, J., \& Cormier, M. (2017, February 9). The public broadcaster's role in the fake news era. Retrieved from: http://policyoptions.irpp.org/magazines/february-2017/thepublic-broadcasters-role-in-the-fake-news-era/

Mathieu. E. (Oct. 17 2018). CBC to air Murdoch Mysteries instead of municipal election. Toronto Star. https://www.thestar.com/news/gta/2018/10/17/cbc-to-air-murdochmysteries-instead-of-municipal-election.html

Missing and Murdered Aboriginal Women. (2019). CBC.ca. https://www.cbc.ca/missingandmurdered/

Moe, H. (2008). Dissemination and dialogue in the public sphere: a case for public service media online. Media, Culture \& Society. Vol. 30(3): 319-336.SAGE Publications

Mosco, V. (2009). The political economy of communication (2nd ed.). Los Angeles, CA: SAGE Publications Ltd. Print

Murdock, G. (2004). Building The Digital Commons: Public Broadcasting In The Age Of the Internet. The 2004 Spry Memorial Lecture. University of Montreal. http://citeseerx.ist.psu.edu/viewdoc/download?doi=10.1.1.627.2917\&rep=rep1\&type= pdf

Nerenberg, K. (Nov. 2018). Federal review of broadcasting and communications faces stiff 
headwinds. Rabble.ca. http://rabble.ca/news/2018/11/federal-review-broadcasting-andcommunications-faces-stiff-headwinds

Numeris. (2018). Audience Measurement in Canada. Print

Örnebring, H. (2007). A Necessary Profession for the Modern Age: Nineteenth Century News, Journalism and the Public Sphere. Media and Public Spheres. Palgrave. $71-8$

Public Policy Forum. (2017). Shattered Mirror: News, Democracy, and Trust in the Digital Age. PDF.https://shatteredmirror.ca/wpcontent/uploads/theShatteredMirror.pdf Pedwell, T. (2016). Half of local TV in Canada could go off air by 2020: report. Global News. https://globalnews.ca/news/2473116/half-of-local-tv-in-canada-could-go-off-air-by2020-report

Raboy, M (1998). Public Service Broadcasting in the Context of Globalization. "Public Broadcasting For The 21st Century” Academia Monograph. University of Luton. Print.

Rowland, W. (2013). Saving The CBC: Balancing Profit and Public Service. Linda Leith Publishing. Toronto. Print

Rowland, W. (2015). "Canada Lives Here: The Case for Public Broadcasting.” Linda Leith Publishing. Toronto. Print.

Savage, P. (2010). Identity Housekeeping in Canadian Public Service Media. In P. Iosifidis. (Ed.), Reinventing Public Service Communication: European Broadcasters and Beyond. Palgrave MacMillan. 273-286.

Soroka, S., Andrew, B., Aalberg, T., Iyengar, S., Curran, J., Coen, S., Hayashi, K., Jones, P., Tiffen, R. (2013). Auntie Knows Best? Public Broadcasters and Current Affairs Knowledge. British Journal of Political Science, 43(4), 719-739. doi:10.1017/S0007123412000555

Srnicek, N. (2017). We need to nationalise Google, Facebook and Amazon. Here's why. The Gaurdian.https://www.theguardian.com/commentisfree/2017/aug/30/nationalisegoogle-facebook-amazon-data-monopoly-platform-public-interest

Taylor, G. (2016). "Dismantling the public airwaves: Shifting Canadian public broadcasting to an online service." International Communication Gazette, 78(4), 349364.doi:10.1177/1748048516632169

Tracey, M. (1998). “The Decline and Fall of Public Service Broadcasting.” Oxford: Oxford University Press. doi: OI:10.1093/acprof:oso/9780198159254.001.00 Thompson, N. (February 19 2018). A Facebook Executive Apologizes To His 
Company-And To Robert Mueller. Wired. https://www.wired.com/story/facebookexecutive-rob-goldman-apologizes-to-company-and-robert-mueller/

Thompson, N., and Vogelstein, F. (March 20 2018). A Hurricane Flatten

Facebook. Wired. https://www.wired.com/story/facebook-cambridge-analyticaresponse/

Spigelman, J. (2013).Defining Public Value in The Age of Information Abundance. in (Eds.) Gregory Ferrell Lowe \& Fiona Martin. The Value of Public Service Media RIPE@2013.44-58

Vaidhyanathan, S. (2018). Anti-Social Media: How facebook Disconnects Us and Undermines Democracy. New York. Oxford University Press.

Waterson, J. (August 23 $3^{\text {rd }}, 2018$ ). Corbyn proposes 'public Facebook' as part of media overhaul. the Guardian. ttps://www.theguardian.com/politics/2018/aug/23/corbynproposes-public-facebook-as-part-of-media-overhaul

What is PSM? (2019). Public Media Alliance. https://www.publicmediaalliance.org/aboutus/what-is-psm/ 